\title{
Inspection of Compressed Natural Gas Cylinders on School Buses
}

Acurex Environmental Corporation

Mountain View, CA

NREL technical monitor:

P. Norton

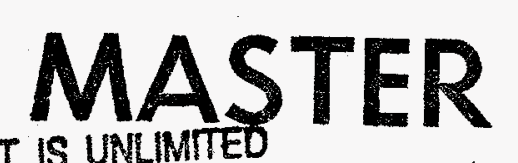

National Renewable Energy Laboratory

1617 Cole Boulevard

Golden, Colorado 80401-3393

A national laboratory of the U.S. Department of Energy

Managed by Midwest Research Institute

for the U.S. Department of Energy

Under Contract No. DE-AC36-83CH10093

Prepared under Subcontract Number YCC-4-14238-01

July 1995 


\section{NOTICE}

This report was prepared as an account of work sponsored by an agency of the United States government. Neither the United States government nor any agency thereof, nor any of their employees, makes any warranty, express or implied, or assumes any legal liability or responsibility for the accuracy, completeness, or usefulness of any information, apparatus, product, or process disclosed, or represents that its use would not infringe privately owned rights. Reference herein to any specific commercial product, process, or service by trade name, trademark, manufacturer, or otherwise does not necessarily constitute or imply its endorsement, recommendation, or favoring by the United States government or any agency thereof. The views and opinions of authors expressed herein do not necessarily state or reflect those of the United States government or any agency thereof.

Available to DOE and DOE contractors from:

Office of Scientific and Technical Information (OSTI)

P.O. Box 62

Oak Ridge, TN 37831

Prices available by calling (615) $576-8401$

Available to the public from:

National Technical Information Service (NTIS)

U.S. Department of Commerce

5285 Port Royal Road

Springfield, VA 22161

(703) $487-4650$ 


\section{DISCLAIMER}

Portions of this document may be illegible in electronic image products. Images are produced from the best available original document. 


\section{Contents}

Page

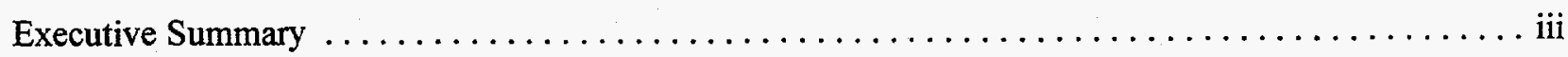

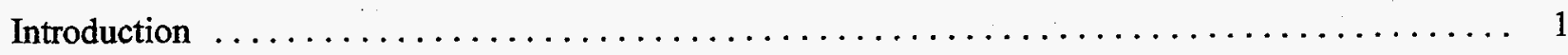

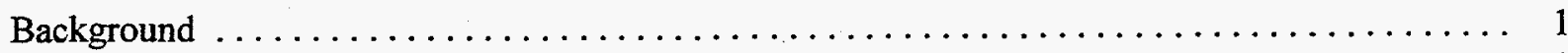

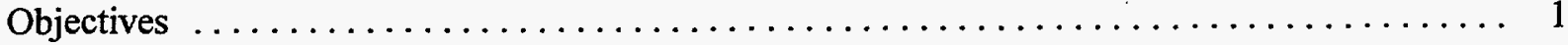

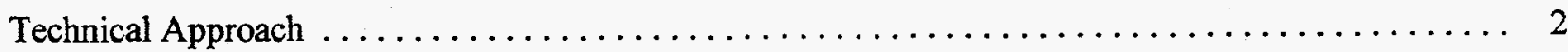

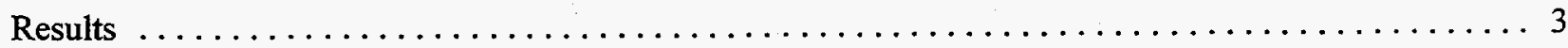

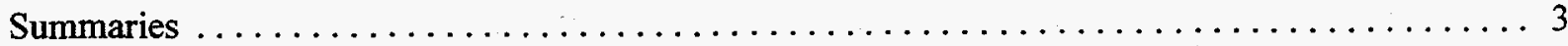

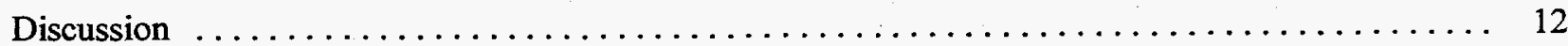

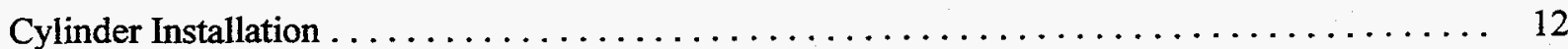

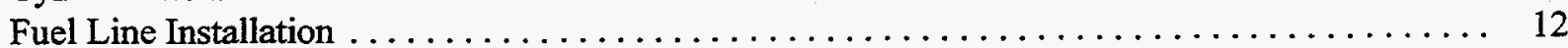

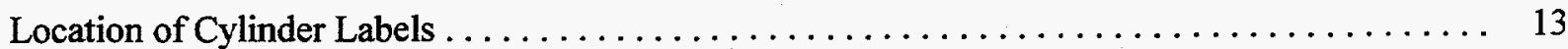

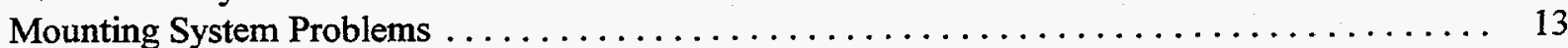

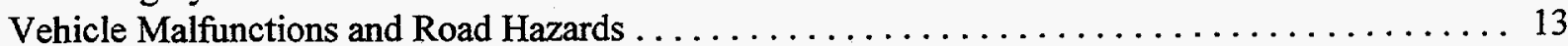

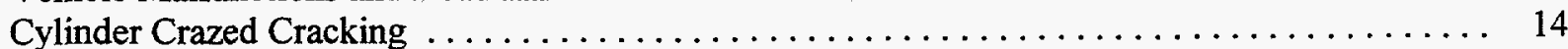

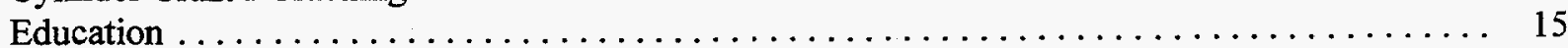

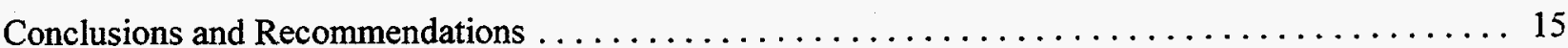

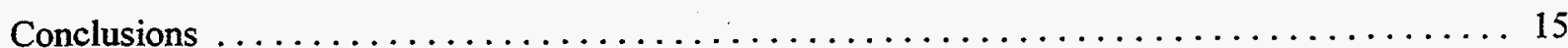

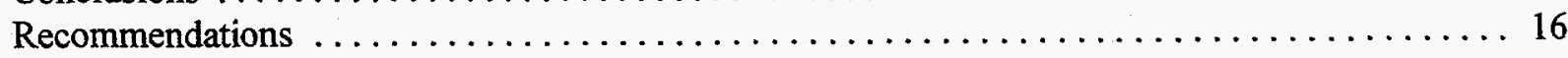

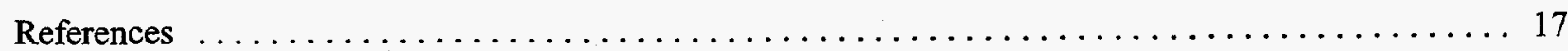

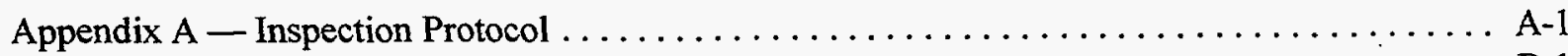

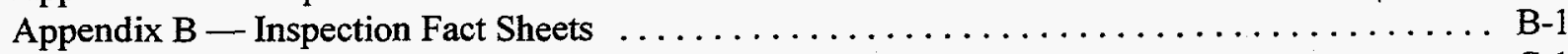

Appendix $\mathrm{C}$ - Description of Vehicle Cylinder Mountings $\ldots \ldots \ldots \ldots \ldots \ldots \ldots \ldots \ldots$ C-1 


\section{List of Tables}

Page

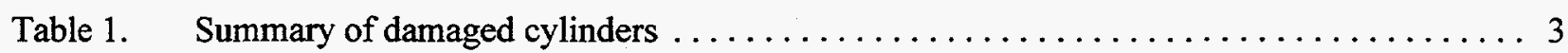

\section{List of Figures}

$\underline{\text { Page }}$

Figure 1. Example of cylinder mounting installation $\ldots \ldots \ldots \ldots \ldots \ldots \ldots \ldots \ldots \ldots$

Figure 2. Scratch along cylinder surface of the Site 2 bus operating in service $\ldots \ldots \ldots \ldots$

Figure 3. Possible burn marks on cylinder surface of first Site 7 bus $\ldots \ldots \ldots \ldots \ldots \ldots$

Figure 4. Nut embedded in cylinder surface of second Site 7 bus $\ldots \ldots \ldots \ldots \ldots \ldots$

Figure 5. Cylinder damage caused by an embedded bolt in a Site 9 bus $\ldots \ldots \ldots \ldots \ldots \ldots$

Figure 6. Cylinder mounting design problem $\ldots \ldots \ldots \ldots \ldots \ldots \ldots \ldots \ldots \ldots \ldots \ldots \ldots$ 


\section{Executive Summary}

The U.S. Department of Energy (DOE) is sponsoring compressed natural gas (CNG)-powered school bus demonstrations in various locations around the country. Early in 1994, two non-DOE-sponsored CNG vehicles equipped with composite-reinforced-aluminum fuel cylinders experienced cylinder ruptures during refueling. Subsequent inspections revealed that the cylinder composite materials were damaged, which led to the ruptures. Ensuring the safety of the CNG vehicles it sponsors is of paramount concern to DOE, so the Department directed the National Renewable Energy Laboratory (NREL) to conduct inspections of DOEsponsored vehicles nationwide.

The objectives of this effort were:

- To inspect the CNG tanks on school buses vehicles sponsored by DOE and to determine if any were damaged

- To gather information on the types of $\mathrm{CNG}$ cylinders and mounting systems installed on the vehicles - To provide site personnel with guidelines for visually inspecting CNG cylinders.

Field inspection protocol and site-survey "fact sheets" were developed to ensure consistent and thorough inspections (Appendices A and B, respectively). Ten different DOE-sponsored sites were inspected during a 3-week period in May 1994. In total, 26 school buses were inspected.

Each of the CNG cylinders on the vehicles at the visited sites was thoroughly inspected for signs of damage and potential problems. Cylinder data, including information on cylinder type, brand, size, and certification date, were recorded on fact sheets. Cylinder mounting systems and fuel lines were also inspected for hazardous conditions. Photographs were taken at each site to supplement the accumulated inspection information.

Acurex Environmental inspectors found that four CNG cylinders at three sites were damaged:

- $\quad$ Site 1 - bolt embedded in composite wrap surface

- $\quad$ Site 2 - discoloration on composite wrap surface and possible burn marks

- $\quad$ Site 2 - metal nut embedded in composite wrap surface

- $\quad$ Site 3 - deep scratch in composite wrap surface.

The cylinders were tagged to indicate that they were unsafe and should not be used until recertified. The site contact, along with the NREL technical monitor, was alerted to the damage. Each of the damaged cylinders was isolated from the remaining vehicle cylinders and its internal pressure reduced to lessen the likelihood of a rupture. The site contacts were advised to contact their local distributors or certified laboratories to have the damaged cylinders tested for structural integrity.

The field inspectors encountered several less severe problems that were common to several of the vehicles and sites. These problems can be categorized as follows:

- Cylinder installation

- Fuel line installation

- Cylinder label location

- $\quad$ System mounting

- Vehicle malfunctions and road hazards

- Education of maintenance personnel. 
In some cases, the cylinder damage and hazardous conditions resulted from careless cylinder installation. On several of the cylinders, the inspection revealed extraneous hardware in and around the cylinder mountings. Frequently, fuel lines were found to be excessively taut or inadequately supported. Many cylinder labels were installed face up, making it difficult for maintenance personnel to view cylinder specifications (such as certification dates and rated pressures). Other labels were found to be either partially or fully hidden from view by the cylinder mounting supports.

Various cylinder mounting designs presented different potential hazards and difficulties for repair and service. In some cases, the cylinder mountings did not completely isolate the cylinders from rigid metal contact. In others, limited access to the cylinders for repair and service presented a problem.

Many site personnel lacked necessary information on proper cylinder maintenance. They did not know what to look for in a visual inspection of the CNG cylinders and were unsure of the necessary frequency for visual inspections. Many maintenance personnel did not know who to contact for cylinder service, recertification, and on-vehicle cylinder inspections.

Because of the cylinder problems encountered during the site visits and the constantly changing status of CNG vehicles nationwide, maintaining high levels of vehicle safety through inspection should be viewed as an ongoing process. Inspections must be performed regularly and site personnel be trained to perform these inspections.

Site inspectors gave each site contact a copy of the Guidelines for Visual Inspection \& Requalification of Fiber Reinforced High Pressure Cylinders (Compressed Gas Association pamphlet No. C-6.2-1988) and briefly explained the pamphlet's contents. This pamphlet should be consulted when developing an inspection program at your site.

Safety training can be supplemented with other informational materials as well. The materials listed below are available free from the National Alternative Fuels Hotline at 800-423-1363.

- Safety First with CNG: An Introduction to CNG Safety for Fleet Operators, 1992, video presented by DOE, NREL, and the Southern California Rapid Transit District, hosted by actress Pam Dawber, 16 minutes, 45 seconds

- $\quad$ Alternative Fuel TIPS (Technical Information on Performance and Safety) for Operators and Owners, April 1995, NREL/SP-425-6966, produced by NREL for the DOE Office of Transportation Technologies. 


\section{Introduction}

\section{Background}

The U.S. Department of Energy (DOE) is sponsoring compressed natural gas (CNG)-powered school bus demonstrations in various locations around the country. Early in 1994, two non-DOE-sponsored CNG pickup trucks equipped with composite-reinforced-aluminum fuel cylinders experienced cylinder ruptures during refueling. As reported by the Gas Research Institute (GRI):

... analysis of the cylinder ruptures on the pickup trucks revealed that they were due to acidinduced stress corrosion cracking (SCC) of the overwrap. This method of failure involves a weakening of the fiber overwrap of the cylinder by a combination of operating stresses and an acidic agent. In one incident, acid was traced to leaking automobile batteries carried in the bed of the pickup. In the second case, the source of the acid was undetermined. In both incidents, the acid was introduced to the underbody cylinder through bolt holes drilled in the bed of the truck directly above the cylinder. The accident investigation cited these bolt holes, as well as the design of underbody stone shields (which allowed prolonged immersion of the cylinders in the acidic solution) as being critical to the cause of failure [1].

The overwrap that GRI refers to is a resin-impregnated fiber that is wrapped around the outside of the gas cylinder for added strength. Modern gas cylinders are either "composite-reinforced" (a metal liner with a fiber/resin overwrap) or "all composite" (a plastic liner with a fiber/resin overwrap).

Because ensuring the safety of the CNG vehicles it sponsors is of paramount concern to DOE, the Department, through the National Renewable Energy Laboratory (NREL), conducted inspections of DOEsponsored vehicles nationwide.

\section{Objectives}

The work had three objectives: inspection, documentation, and education. Each objective is discussed in greater detail in the following sections.

\section{Inspection}

First, inspectors visited sites where CNG-powered school buses sponsored by DOE are based, and inspected the CNG cylinders for damage. Responding to a concern that the cylinder mounting systems may have contributed to the tank ruptures on the two non-DOE vehicles, the inspectors also reviewed the cylinder mountings. At sites where vehicles were still under construction by the manufacturer and not available for inspection, the manufacturer was contacted to obtain cylinder brand, size, and installation information.

\section{Documentation}

Second, information learned during the inspections was collected for DOE. This information included the type of mounting systems used; the brand, size, and type of construction of the cylinders; and any present or potential cylinder damage to DOE-sponsored vehicles in service. In this report, the possible causes of the cylinder damage discovered are described. The final section, Conclusions and Recommendations, includes suggestions on how cylinder damage could be reduced or avoided in the future. 


\section{Education}

Third, the inspectors found that the education and awareness of site personnel, in terms of cylinder damage detection, needed to be increased. The site visits allowed the inspectors to talk with the individuals who are most likely to find cylinder damage and hazardous conditions (i.e., mechanics, shop foremen, site supervisors). When possible, these individuals also observed the inspection procedure, experiencing firsthand the amount of time and thoroughness required for complete and adequate cylinder inspection. The inspectors answered questions regarding items such as inspection procedures, results, and cylinder information immediately or through follow-up correspondence.

To provide a reference for recognizing significant cylinder damage, the inspectors gave a copy of the Guidelines for Visual Inspection \& Requalification of Fiber Reinforced High Pressure Cylinders (Compressed Gas Association [CGA] pamphlet No. C-6.2-1988) to each site contact and briefly explained the pamphlet's contents. These inspections served to educate fleet users about additional safety measures that should be implemented with the newer alternative fuel systems.

The results of this work are detailed in a three-volume report submitted to NREL in September 1994 [2,3,4].

\section{Technical Approach}

A field inspection protocol and site-survey "fact sheets" were produced to ensure that inspections were consistent and thorough. The protocol contained the list of procedures that the inspectors followed at each site. The fact sheets served as checklists to ensure that the inspectors obtained all the required information at each location. The uniformity of the protocol and fact sheets enable results to be easily compiled and compared between various sites and inspectors. Sample copies of the protocol and fact sheets used in the inspections are provided in Appendices A and B, respectively. The fact sheets, with the recorded site information, comprised Volume II of the original CNG cylinder inspection report [3].

Each of the CNG cylinders on the vehicles at the visited sites was thoroughly inspected for signs of damage and/or potential problems. The brackets and fixtures that support the CNG cylinder were checked for tightness, adequate insulating material, support, and operation. The CNG cylinders were checked for inadvertent contact with frame or chassis mechanisms (i.e., cables, fuel lines, or body parts). All cylinders were inspected for wear caused by unexpected abrasions as a result of vehicle damage, road debris, vehicle maintenance, objects wedged between cylinders, or similar conditions that could result in damage. Cylinders were also inspected for any sign of chemical attack that might lead to stress-corrosion failures.

All CNG cylinders were inspected for current and valid certifications. Inspectors recorded cylinder brand, size, type, and certification dates. Cylinder manufacturers were consulted when the labels contained illegible markings. For vehicles still under construction and not yet delivered, the manufacturers were contacted to obtain cylinder specifications and mounting information as available.

Photographs were taken at each site to supplement the accumulated cylinder information. Any unusual or questionable findings were thoroughly photographed and labeled. Vehicle cylinders and installation hardwarewere also photographed to document the different cylinder types and mounting systems. Figure 1 is an example of the photographs taken to illustrate cylinder and mounting system installations. Copies of these photographs were compiled in Volume III of the original CNG cylinder inspection report [4].

Where damaged cylinders were found, the site inspector tagged the cylinders and recommended that either the vehicle be taken out of service or the damaged cylinders be isolated from the rest of the fuel system until the questionable cylinders were repaired or replaced and then recertified. In addition, the fleet manager/site contact was informed that the pressure in any damaged cylinder should be reduced and/or safely vented to 


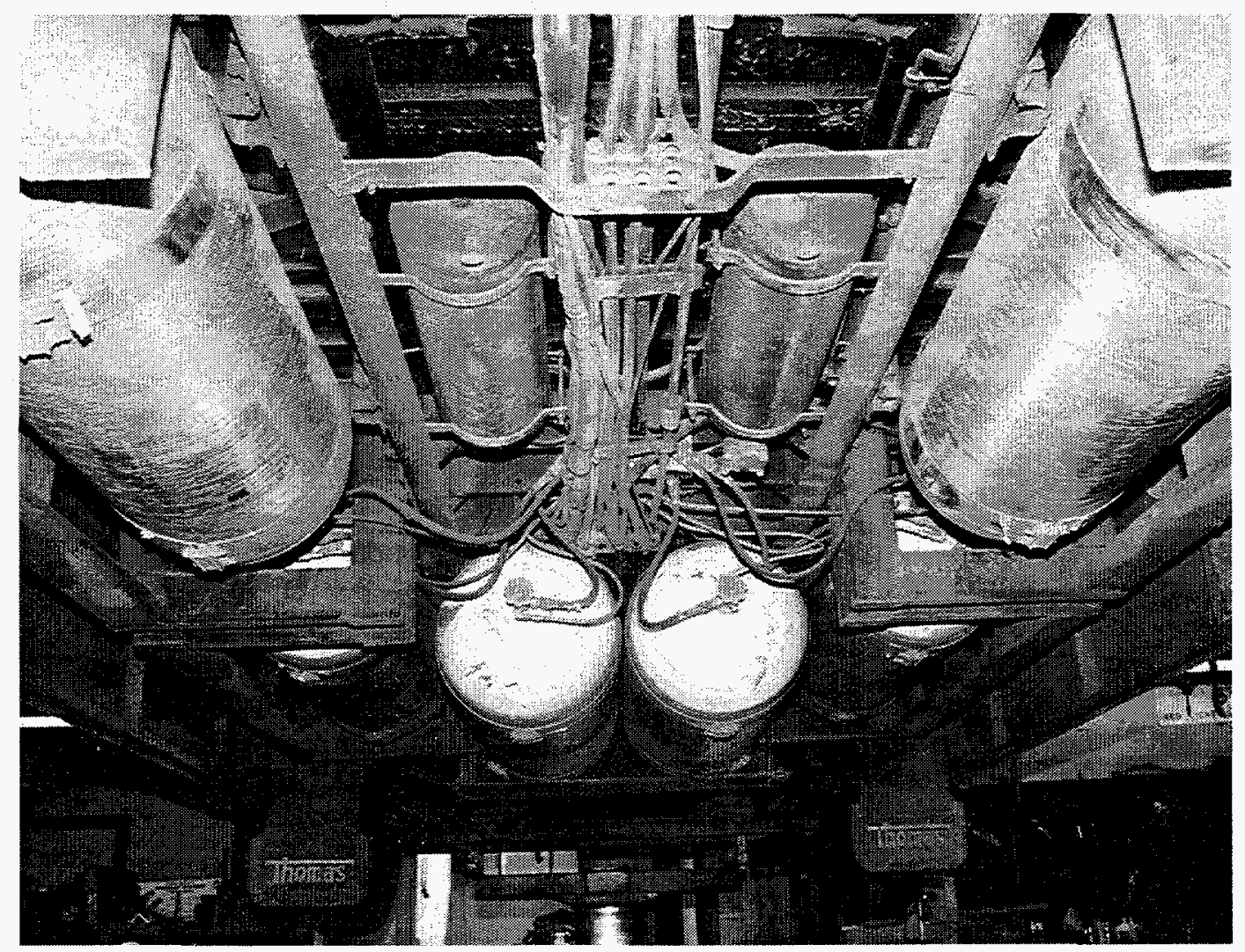

Figure 1. Example of cylinder mounting installation

reduce the potential risk of rupture. The inspector contacted the NREL technical monitor by telephone about any unsafe conditions found.

\section{Results}

The inspections uncovered damage to four CNG cylinders on four different vehicles at three sites. Table 1 briefly summarizes the damaged cylinders tagged during the inspections. More detailed descriptions of the inspection findings are presented in Appendix C.

Table 1. Summary of damaged cylinders

\begin{tabular}{l}
\hline \multicolumn{1}{c}{ Type of Cylinder Damage } \\
\hline Bolt embedded in composite wrap surface \\
Discoloration on composite wrap surface, possible burn marks \\
Metal nut embedded in composite wrap surface \\
Deep scratch in composite wrap surface
\end{tabular}

\section{Summaries}

The following sections summarize the information gathered during visits to sites with in-service vehicles.

Two Acurex Environmental inspectors visited 10 sites during a 3-week period in May 1994. The results of the individual site visits are summarized below. During the visits, the inspectors assigned cylinders and cylinder mounting systems arbitrary letter and number designations for identification and documentation purposes. That nomenclature has been carried forward to this report. 


\section{Site 1}

\section{General Information}

This site operates four DOE-sponsored school buses that were put into service in September 1993. Each vehicle has four $\mathrm{CNG}$ cylinders mounted mid-vehicle between the front and rear wheels. These vehicles are not emergency vented and do not operate with a reserve tank. An emergency vent is a tube or pipe that leads from a CNG cylinder or a manifold of several CNG cylinders to a point above the vehicle to allow for the release of natural gas in the event of an emergency. A reserve tank is a regular CNG cylinder that, after being filled, is manually shut off from the rest of the fuel system and is manually opened only when the vehicle uses up its remaining primary supply of fuel.

\section{Inspection Results}

One bus experienced a line rupture during fueling in 1993. The cause of the rupture is still unknown. As a precaution, the fuel lines on the bus were covered with protective rubber hose and fastened away from any loose contact with other lines and CNG cylinders. The fuel lines of the other vehicles were not insulated with rubber hose or secured in this manner, and many fuel lines were found lying against the cylinders. The cylinder and fuel line wear resulting from this contact appeared to be negligible and the situation was not considered hazardous. The maintenance supervisor was notified of the findings. Several of the cylinders on each vehicle showed crazed cracking, a common condition believed to be a result of permanent tank expansion after testing. Crazed cracking is treated in more detail in the Discussion section of this report.

\section{Site 2}

\section{General Information}

This site has two DOE-sponsored school buses equipped with wheelchair lifts. One of the buses was placed into service in early May 1994, only 2 weeks prior to the inspection. The other had not yet entered service, pending the correction of safety inspection items noted by local inspectors. Both vehicles have four CNG cylinders mounted mid-vehicle between the front and rear wheels. These vehicles are not emergency vented and do not operate with a reserve tank.

\section{Inspection Results}

Cylinder D of the bus operating in service was tagged and isolated from the vehicle's remaining three cylinders. The inspection revealed a deep scratch in the composite wrap (approximately $0.05 \mathrm{in}$. in depth) along the bottom surface of the cylinder. Figure 2 is a photograph of the damage. A pitted hole, of approximately the same depth as the scratch, and numerous minor abrasions near the front cylinder mount were also found on the cylinder surface.

The damaged cylinder was tagged, and the site contact and shop supervisor were alerted to the condition. The site contact confirmed that the cylinder shut-off valve would be closed and the cylinder vented to reduce the pressure and the possibility of rupture. The bus was permitted to remain in service, but the damaged cylinder was to be isolated from the vehicle's fuel system until it was certified or replaced.

Cable looms, shrouded in plastic, were found routed along the top of the two inboard cylinders (B and C) on both buses. Cable looms are small mounts designed to hold cables and/or fuel lines firm and away from possible poiints of abrasion. 


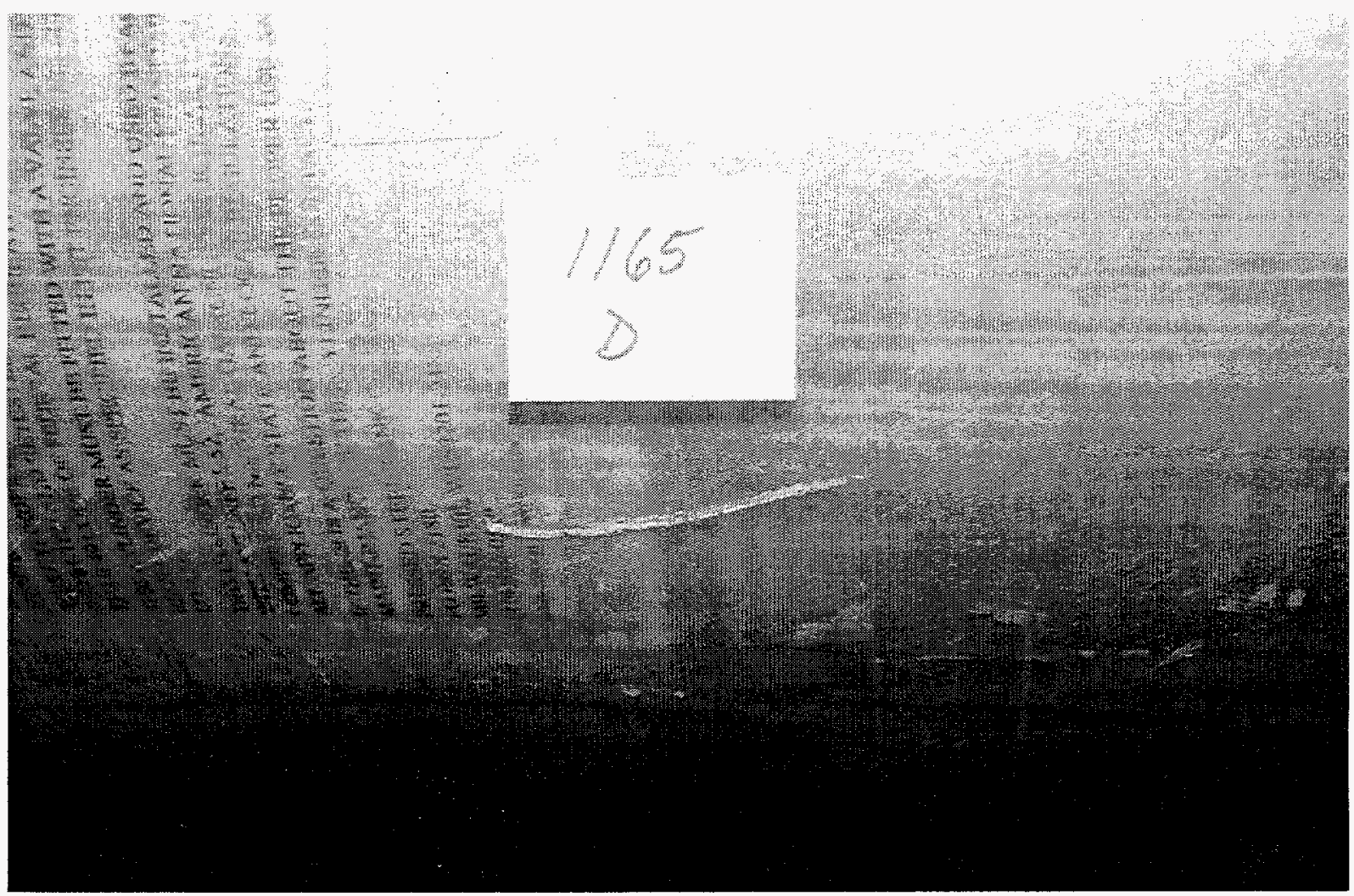

Figure 2. Scratch along cylinder surface of the Site 2 bus operating in service

The flexible steel-braided fuel lines, which ran from the cylinders to a common manifold, were not tied down and were free to rub against the vehicle framing, fuel cylinders, and each other. No abrasions caused by these conditions were apparent at the time of the inspection, but the site contact was informed of the conditions and advised to check them periodically and discuss with the manufacturer the possibility of rerouting the lines to reduce the likelihood of future problems.

The scratch and pitted hole on cylinder D of the operating bus most likely resulted from road debris kicked up onto the cylinder. The operational service area for these buses, as well as the storage/maintenance yard at the site facility, contains a number of rough/unpaved roads with many stones. There are no gravel guards for the outboard cylinders on the buses, only mud flaps. Because the operating bus sustained damage after an in-service period of only 2 weeks, the likelihood of future damage similar to that found during the inspection is high. For these reasons, the inspector advised the site contact to discuss with the manufacturer the possibility of more substantial shielding and gravel guards for the buses.

In a later phone conversation with the site contact, it was learned that site personnel had decided to replace cylinder $\mathrm{D}$ on the operating bus instead of testing and recertifying the cylinder.

\section{Site 3}

\section{General Information}

This site operates two DOE-sponsored CNG school buses, which entered service in February 1994. The vehicles are equipped with wheelchair lifts, and fitted with four CNG cylinders. Two of the cylinders are mounted mid-vehicle, between the front and rear wheels. The remaining two cylinders are mounted behind the rear wheels. All the cylinders are mounted longitudinally on the outside of the vehicle frame rails. The vehicles have an emergency venting system and operate without a reserve tank. The cylinders are each mounted in a self-contained carrier unit with a gravel guard along the bottom surface. Refer to Appendix C for a more detailed description of the cylinder mounting system. 


\section{Inspection Results}

The inspection revealed no damage or hazardous conditions. A few minor scratches were found on the cylinders, but they were not significant and did not constitute a hazard. Several instances of crazed cracking were noted.

\section{Site 4}

\section{General Information}

This site operates one DOE-sponsored CNG school bus, which entered service in May 1993. The vehicle is equipped with a wheelchair lift, and fitted with six CNG cylinders. Four of the cylinders are mounted midvehicle, between the front and rear wheels. The remaining two cylinders are mounted behind the rear wheels. All six of the cylinders are mounted longitudinally on the outside of the vehicle frame rails. The vehicle has an emergency venting system and operates without a reserve tank. The cylinders are mounted within carrier units that have gravel guards along the bottom surfaces.

\section{Inspection Results}

The fuel lines, which run from the cylinders to a common manifold line, are hard plumbed. Only one expansion loop was present in the installation. In this type of arrangement, the fittings and fuel lines may be subjected to a greater risk of fatigue failure, which is a potential problem. When alerted to this condition, the shop foreman mentioned that he had similar concerns about the design, but that it satisfied local regulations. The shop foreman said that he would inquire about installing lines with expansion loops during his next conversation with the local distributor.

Several of the cylinders exhibited crazed cracking.

\section{Site 5}

\section{General Information}

This site operates three DOE-sponsored school buses, which were put into service in September 1993. The vehicles have six CNG tanks mounted mid-vehicle, between the front and rear wheels. All of these vehicles are emergency vented and operate with a reserve tank.

\section{Inspection Results}

Two of the fuel lines on one bus were found to be excessively taut. This was not considered to be a hazardous condition of immediate concern. The shop foreman was alerted, and he informed the inspector that he would notify the company that services their CNG vehicles of this condition.

Cylinder $\mathrm{D}$ on a second bus had a noticeable rust line at the point where the composite material ends. The rust was not severe and the cylinder was not considered unsafe.

Several of the cylinders on each vehicle showed crazed cracking. 


\section{Site 6}

\section{General Information}

This site operates two DOE-sponsored school buses, which were put into service in September 1993. The vehicles have six CNG tanks mounted mid-vehicle, between the front and rear wheels. Both vehicles are emergency vented and operate with a reserve tank. The upper section of these cylinders could not be seen without a mirror and flashlight.

\section{Inspection Results}

Two of the fuel lines on one bus were found to be excessively taut and rubbing against the cylinder cage. The shop foreman was alerted, and the problem was corrected immediately by rotating and tightening the threaded connection, which, in effect, lengthened the fuel line. As an additional safety measure, a rubber insulator was wrapped around the line at the point where the fuel line had contacted the cage.

It was noted that several cylinders had oil splashed on them. This was assumed to be the result of a leak elsewhere on the vehicle or a splash from the road. The cylinder manufacturer was contacted to verify that this substance would not affect the performance of the cylinder.

Several of the cylinders on these vehicles exhibited crazed cracking.

\section{Site 7}

\section{General Information}

This site operates three DOE-sponsored school buses, which were put into service in early April 1994. The vehicles have four CNG cylinders mounted in the rear of the buses, behind the rear wheels. The cylinders are composite-reinforced aluminum. The vehicles have an emergency venting system and operate without a reserve tank. The manufacturer labels on the individual cylinders were hidden by the cylinder mounting straps, so the cylinder specifications could not be recorded at the time of the inspection. However, the serial numbers for these cylinders were factory stamped into the head of the cylinder. These serial numbers were recorded and the cylinder manufacturer was contacted to obtain the certification dates and other cylinder specifications. These vehicles did not have a vehicle system label. Such a label would contain the system specifications and cylinder retest date and be readily available to maintenance and site personnel.

\section{Inspection Results}

Cylinder D of one bus was tagged and isolated from the vehicle's remaining three cylinders. Inspection of the cylinder surface yielded three areas of discoloration. The source of the gray/black marks was unknown, but a tactile inspection of the area revealed a bubbled texture and possible burn marks. In the interests of safety, the cylinder was tagged for further testing. Figure 3 is a photograph of the marks on the cylinder surface.

Cylinder B of a second bus was tagged and isolated from the vehicle's remaining three cylinders. Upon inspection, a metal nut was found wedged between the steel support band and the side of the cylinder. The nut was partially embedded into the composite wrap of the cylinder. Figure 4 is a photograph of the embedded nut. The nut appeared to be of the type used for bracket and cylinder installation.

The site contact and shop supervisor were alerted to the damage to the cylinders. The cylinder shut-off valves were closed, and the cylinders were vented to reduce the pressure. The vehicles were allowed to remain in service, with the damaged cylinders isolated from the rest of the fuel system. 




Figure 3. Possible burn marks on cylinder surface of first Site 7 bus

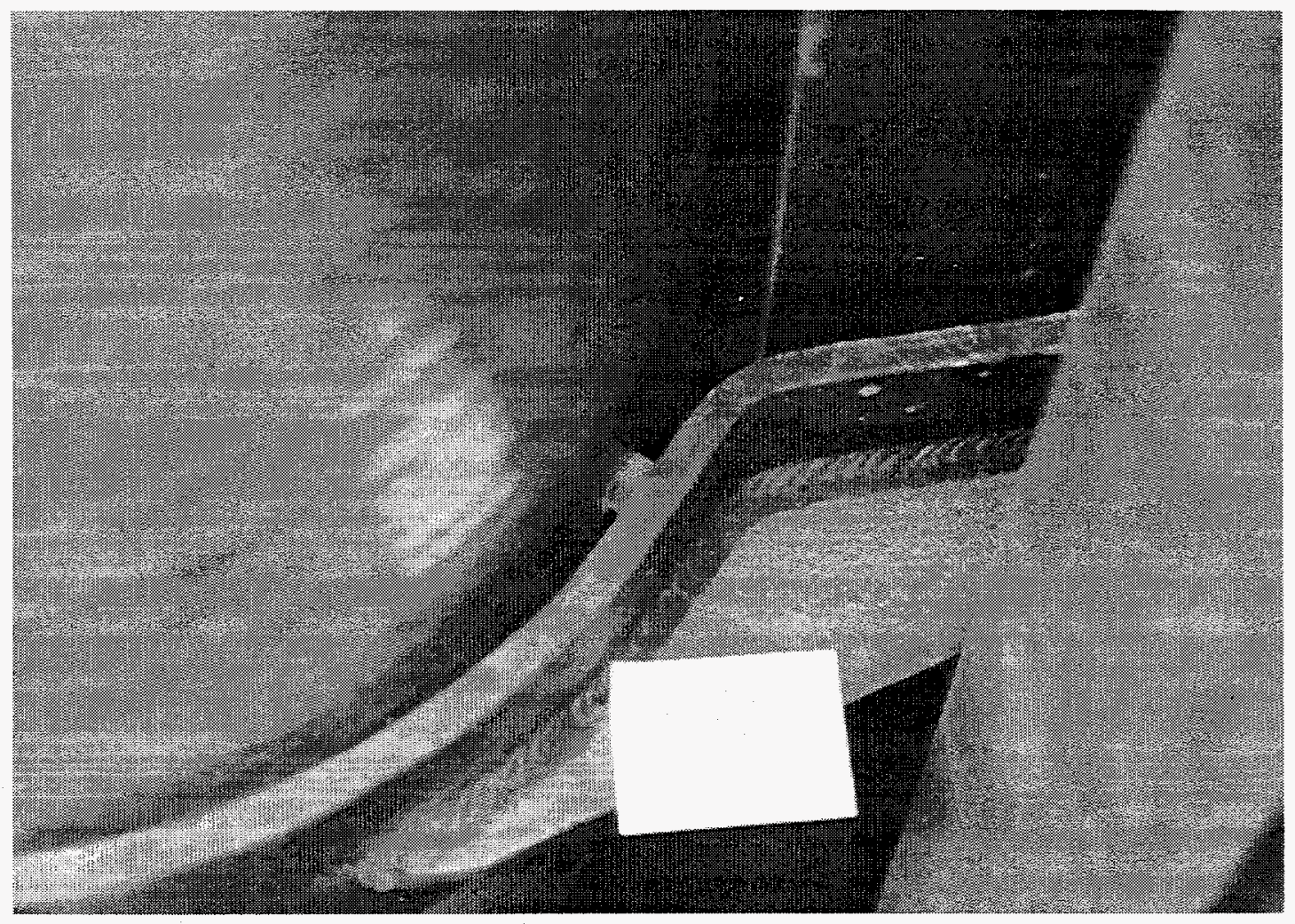

Figure 4. Nut embedded in cylinder surface of second Site 7 bus 
The rubber insulators on some of the cylinders, particularly cylinder $C$ on the first bus, had shifted in the steel support bands. Although no metal-to-composite contact had occurred on cylinder $C$ of this bus, the insulator had moved more than an inch out of the support. Apparently the glue used to fix the rubber insulators to the steel support bands had failed, allowing the insulators to move relative to the supports. Because the steel support bands were not loose and all of the shifting was toward the front of the mounts, it appears that the insulators shifted during the installation of the cylinders.

The bolt used to clamp the upper and lower steel support bands on the forward mount between cylinders B and $\mathrm{C}$ on the second bus was close to contacting both cylinders, though not touching. It appears that the two cylinders were not installed parallel to one another, but rather were aligned such that the gap between them narrows toward the cylinder valves in the front. This was not considered to be hazardous, but the arrangement should be checked periodically to make sure that no interference or contact is causing abrasion of the cylinder surfaces.

The damage and the hazardous conditions mentioned here were discussed with the site contact, who informed the inspector that the vehicles would be taken to the local distributor so that the damaged cylinders could be tested and repaired/recertified. Additionally, the potential hazards identified would be discussed with the local distributor so that they could be corrected. The cylinders on the two buses were hydrotested and recertified or replaced by a local laboratory.

\section{Site 8}

\section{General Information}

This site operates three DOE-sponsored school buses, which were being put into service during the time of the inspections. Each vehicle is equipped with a wheelchair lift and has four CNG cylinders mounted midvehicle between the front and rear wheels. These vehicles are emergency vented and operate without a reserve tank.

\section{Inspection Results}

Cable looms, shrouded in plastic, were found routed along the top of the two inboard cylinders (B and C) on the buses. Similarly, the flexible fuel lines, which ran from the cylinders to a common manifold, were not tied down and were free to rub against the vehicle framing, fuel cylinders, and each other. There did not appear to be any abrasions caused by these conditions at the time of the inspection, but the site contact was advised to check the lines periodically and discuss with the local distributor the possibility of rerouting the lines to avoid future problems.

Vehicle undercoating material covered large portions of the upper surfaces of some of the cylinders. This condition was not considered hazardous to the cylinders.

One of the gravel guard strut supports next to cylinder B on one bus had been bent in toward the cylinder. This condition was not considered hazardous because there was still clearance between the strut and the cylinder, and the strut remained functional.

Several of the cylinders exhibited crazed cracking. 


\section{Site 9}

\section{General Information}

This site operates two DOE-sponsored school buses, which began service in late 1993. Both vehicles have four CNG cylinders mounted in the rear of the bus, behind the rear wheels. The cylinders are compositereinforced aluminum. The vehicles have an emergency venting system and operate without a reserve tank. The distance from the road to the underside of the cylinders is $25 \mathrm{in}$. The manufacturer's labels on the individual cylinders were hidden from view by the cylinder mounting straps and the cylinder specifications could not be recorded at the time of inspection. However, the serial numbers for these cylinders were factory stamped into the head of the cylinder. These serial numbers were recorded and the cylinder manufacturer was contacted to obtain the certification dates and the other cylinder specifications. These vehicles did not have a vehicle system label, which would contain the system specifications and cylinder retest date and be readily available to maintenance and site personnel.

\section{Inspection Results}

During the inspection of one bus, a bolt was found wedged between the chassis frame rail and the side of cylinder B. The head of the bolt was partially embedded (approximately $0.2 \mathrm{in}$.) into the composite wrap of the cylinder. Figure 5 is a photograph of the embedded bolt.

When this damage was discovered, the cylinder shut-off valve was closed and tagged to indicate that the cylinder was damaged and that the valve should not be opened. This isolated the cylinder from the vehicle's remaining three cylinders. The site contact and shop supervisor were informed about the cylinder's status. The vehicle was permitted to remain in service without using the damaged cylinder. The vehicle had just finished refueling, so the cylinder was at full pressure. At the end of the daily route, the shop supervisor said he would open the valve before refueling, reduce the pressure in the cylinder, and re-close the valve on the tagged cylinder.

The embedded bolt appeared to be of the type used for the bracket and cylinder installation. On the same vehicle, an extraneous piece of CNG fuel line was wedged between the chassis frame rail and the adjacent cylinder (cylinder C). This line had not caused any damage to the cylinder's composite wrap and was easily removed by hand.

The inspector noted that the shut-off valve was difficult to turn and it was hard to determine when the valve was in the fully closed position.

The cylinders on the vehicles seemed to have been subjected to unfavorable environmental conditions. The aluminum ends of the cylinders showed signs of oxidation, which was beginning to work its way beneath the composite wrap. This condition did not appear to be critical at the time of the inspection, but should be checked periodically. In addition, the outboard cylinders of the bus with the damaged cylinder were covered with sand. This did not appear to cause a problem to the cylinders themselves, but the buildup of sand around the shut-off valve may partially explain why it was difficult to turn the damaged cylinder's shut-off valve and to determine when it was fully closed. 


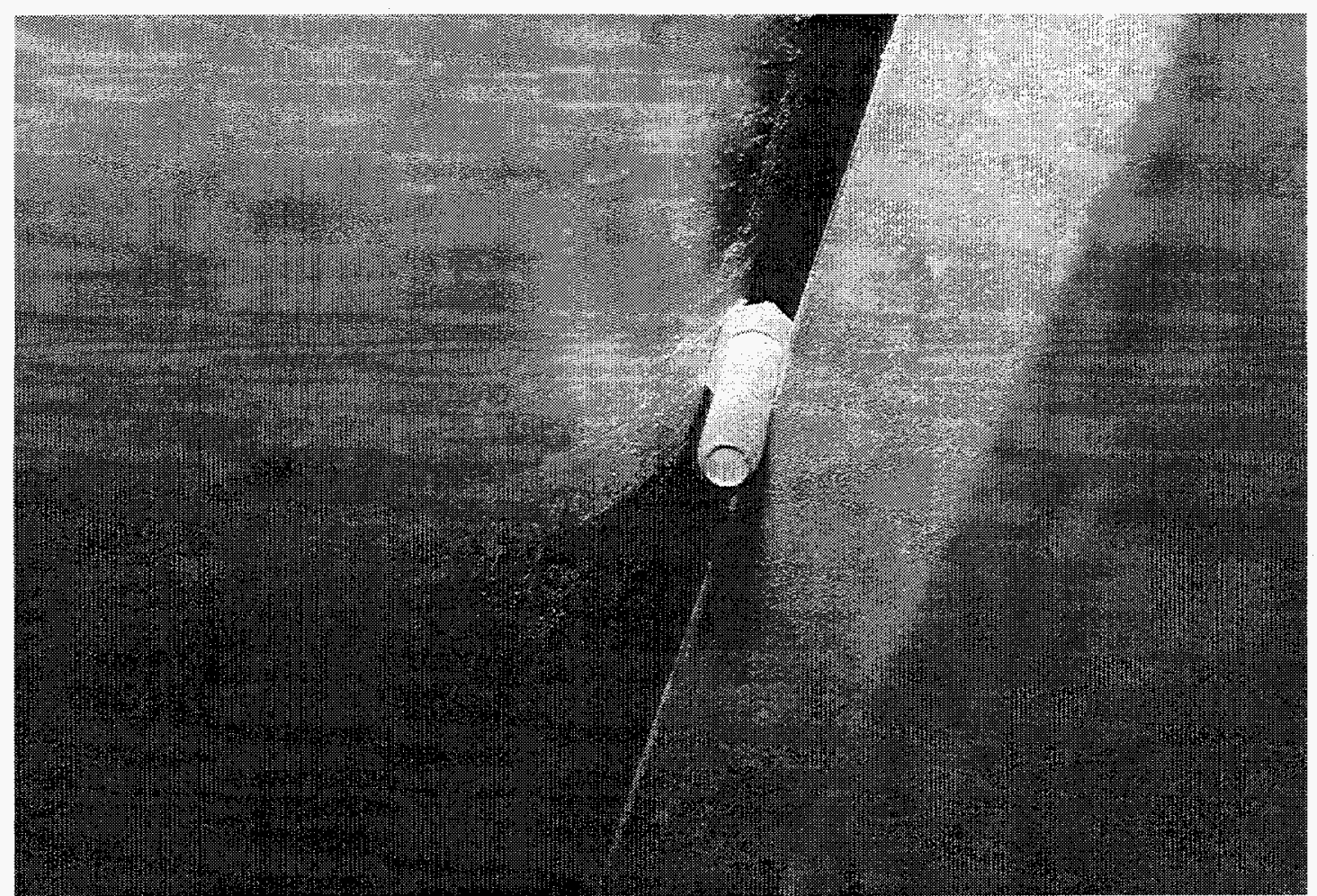

Figure 5. Cylinder damage caused by an embedded bolt in a Site 9 bus

Site 10

\section{General Information}

This site operates four DOE-sponsored CNG school buses. Two of the school buses entered service in early 1993. These two vehicles have three composite-reinforced-aluminum CNG cylinders mounted behind the rear wheels. These vehicles are not emergency vented and do not operate with a reserve tank. The distance from the road to the underside of the cylinders is $22 \mathrm{in.} \mathrm{Because} \mathrm{of} \mathrm{the} \mathrm{limited} \mathrm{space} \mathrm{of} \mathrm{the} \mathrm{mounting}$ application, the top portion of the cylinders, between the chassis frame rails, could not be viewed from all angles. The length of the cylinders along the top could be viewed, but neither a line-of-sight perpendicular nor a tactile inspection could be accomplished without removing the cylinders. The limited visual inspection did reveal that no foreign objects were in contact with the cylinders and that the cylinders were not subjected to any unusual or hazardous conditions. Many of the cylinder manufacturer's labels were concealed by the cylinder mounting brackets. A couple of labels were partially visible, so the cylinder manufacturer was identified. Subsequently, complete cylinder specifications were obtained.

The third and fourth school buses entered service in early 1994. These vehicles have six compositereinforced-steel CNG cylinders mounted mid-vehicle, between the front and rear wheels. Three cylinders are mounted end to end outside the chassis on the driver side and three are mounted end to end outside the chassis on the passenger side of the vehicle. The vehicles have an emergency venting system and operate without a reserve tank. The distance from the road to the underside of the cylinder is approximately 17 in. These cylinders are mounted within a carrier with a gravel guard along the bottom surface. Refer to Appendix $\mathrm{C}$ for a more detailed description of the cylinder mounting system.

\section{Inspection Results}

On one bus, minor road damage to the shielding was noted on cylinders $C$ and $F$. Neither instance of damage prevented the shielding from functioning. 
The front portion of cylinder $A$ on a second bus was rubbing against the gravel guard and a CNG fuel line. This problem had caused no damage to the cylinder, fuel line, or shielding, and was easily corrected by the maintenance staff.

On both buses, a dark oily stain was noticed around most cylinder and fuel fitting threaded connections. This stain was suspected to stem from the pipe dope used on the threaded connections. The maintenance supervisor was advised of the stain. The odor of natural gas was not apparent and the stain was not considered to be a hazardous condition.

The cylinder support clamps of the first bus were covering the cylinder labels. These cylinders did not have the serial number stamped in the cylinder head, so some information was not obtained at the time of inspection. The vehicle and cylinder manufacturers were contacted and the missing specifications were obtained.

All of the composite reinforced steel cylinders at this site exhibited crazed cracking.

\section{Discussion}

Several problems encountered during the field inspections were common to a number of the vehicles and sites. These problems involved cylinder installation, fuel line installation, the location of cylinder labels, mounting systems, vehicle malfunctions and road hazards, and education of maintenance personnel. Each problem is discussed in further detail in the following sections.

\section{Cylinder Installation}

Many instances of damage and hazardous conditions encountered by the inspectors resulted from careless cylinder installation. On several of the cylinders inspected, extraneous hardware was found in and around the cylinder mountings. Fuel lines were frequently found to be excessively taut or inadequately supported. Over the course of the inspections, a bolt, a nut, a screwdriver, and a drill bit were found either wedged into or lying against the cylinders.

Additionally, a number of minor scratches were seen on cylinders near their mounting brackets. These types of scratches typically result from the cylinders being shifted in their mounts when they are being positioned during installation.

\section{Fuel Line Installation}

A common source of potential problems was found in the installation of the fuel lines. On cylinder applications that used steel braided fuel lines, several lines were found to be taut and/or rubbing against the chassis or cylinder carrier. Cylinders in the same location on different vehicles had taut lines, giving the impression that a longer line was not available at the time of installation, so a shorter line was installed instead.

Additionally, many fuel lines were not adequately supported, and were found lying against frame parts or the cylinders themselves. This caused wear to the lines as a result of vibration. Fortunately, the steel braided lines are not easily worn by abrasion, but with time significant damage may occur, especially when the lines are in contact with the cylinder composite wrap or other steel braided lines. One vehicle experienced a CNG fuel line failure. As a result of that failure, preventive maintenance was performed to insulate and support the remaining fuel lines on that particular vehicle. The actual cause of the line rupture was unknown. 


\section{Location of Cylinder Labels}

Many cylinder labels were installed face up, making it difficult for maintenance personnel to view cylinder specifications (such as certification dates). During the inspections, a telescoping mirror and light were used to view these labels so that cylinder specifications could be obtained. Positioning these labels in a more convenient location is not a simple task. When installed, the cylinder is rotated according to the position of the cylinder valve and desired fuel line routing. The cylinder valve is screwed into the cylinder head and the cylinder is rotated and fastened in place as the plumbing permits. This causes the cylinder label to be located in random locations, not necessarily where they can be easily viewed. To increase the chances of a label being easily visible, some cylinders have two labels on opposite sides of the cylinder. One cylinder company suggests another solution - that installers record the cylinder label specifications on a separate label and apply it to the cylinder after installation. This label would be fixed to the cylinder, but it is not known whether it would remain intact and be able to endure the rigors of vehicle service.

In the worst cases encountered, many of the cylinder labels were either partially or fully hidden by the cylinder mounting support. Unless an additional system label is available and easily viewed, site personnel do not know when cylinders are due for recertification. If a system label does exist, the label would have to be updated when cylinder recertifications are performed. To complicate matters further, some vehicles contain cylinders with different certification dates. Therefore, the system label would need to contain all cylinder certification dates or at least the earliest cylinder recertification date.

Some cylinder manufacturers have the cylinder serial numbers factory stamped into the domed portion of the cylinder. These stamped serial numbers are easily seen and the cylinder manufacturer can be contacted directly to obtain certification dates and other cylinder specifications.

\section{Mounting System Problems}

The various cylinder mounting designs and installation types possess different potential hazards and/or difficulties for repair and service.

Some rubber support band insulators do not completely isolate the cylinder from rigid metal contact. The intermediate bracket remains in direct contact with the cylinder as the band threads through the bracket, as shown in Figure 6.

In certain applications, cylinders are not readily accessible. Many cylinder mounting systems are installed while the vehicle body is not attached to the chassis and the installation brackets are fully accessible. When recertification is due, or cylinder service is necessary, these brackets are no longer readily accessible and it is very difficult to remove the cylinders. Some designs left insufficient room for access to the support band mounting bolts, as a service technician has reported while trying to remove a damaged cylinder found at one site.

In another mounting design, the cylinders cannot be removed from the lower part of the carrier; they must be removed from the top. This means the entire cylinder carrier must be lowered from the vehicle in order to have the clearance and accessibility to remove the cylinders from the top. In the cylinder arrangement where three tanks are placed end to end, the carrier is more than $15 \mathrm{ft}$ long and its removal as a unit is extremely awkward. Additionally, an entire bank of cylinders has to be dropped to service one cylinder.

\section{Vehicle Malfunctions and Road Hazards}

Vehicle malfunctions and road conditions can cause unexpected cylinder damage and hazardous conditions. An inspection performed on cylinders on a heavy-duty truck as part of another program 


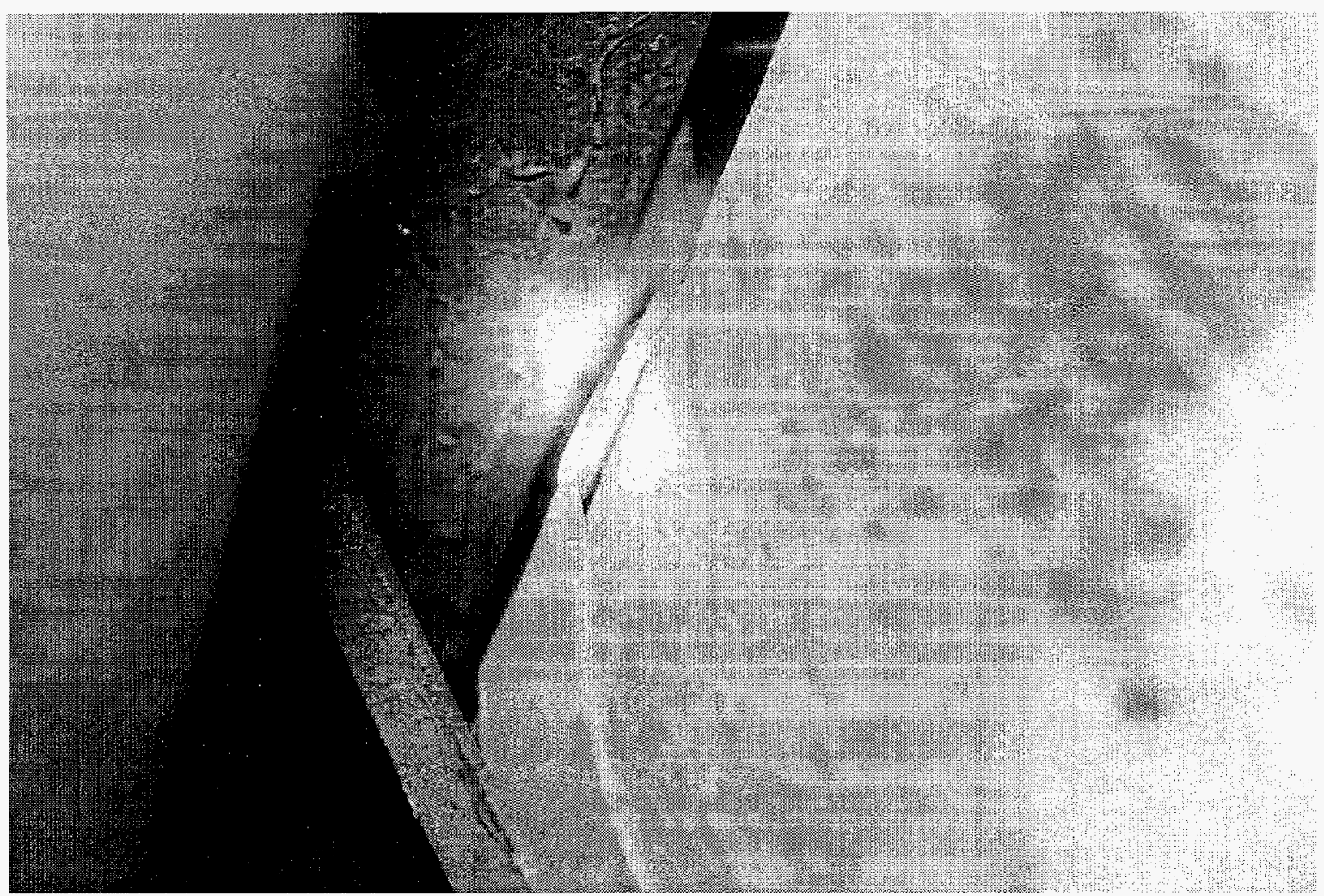

Figure 6. Cylinder mounting design problem

uncovered cylinder cuts and a burn that had occurred during vehicle in-service operation [5]. The cylinder cuts and burn mark were believed to have resulted from cylinder contact with the vehicle exhaust after the exhaust pipe came loose and shifted during service.

Another vehicle inspection turned up a leaking power steering line, which left the cylinder covered with power steering fluid. When questioned about this condition, the cylinder manufacturer responded that power steering fluid would have no adverse effects on the cylinder's construction and safety. This scenario is reminiscent of the rupturing cylinder incidents on the light-duty trucks. In this instance

however, the substance was not considered to be reactive with the cylinder itself and the fluid was notable to pool around the cylinder as was the case with the rupturing cylinders on the light-duty trucks.

Road hazards also contribute to cylinder damage. Road debris kicked up underneath the vehicles can cause damage to cylinder shields or the cylinders themselves. One bus that sustained damage to a cylinder after only 2 weeks in operation is a case in point. The operational environment of the vehicles should be taken into consideration when determining the requirements for adequate shielding and gravel guards.

\section{Cylinder Crazed Cracking}

The inspection of composite reinforced steel cylinders revealed an unusual condition. Of the cylinders inspected, approximately $90 \%$ were found to have cracks running around the circumference of the cylinder composite wrap. The average depth of these cracks was approximately $0.1 \mathrm{in}$. The cylinders that displayed this condition contained anywhere from one to a dozen such cracks.

A representative of the cylinder manufacturer was contacted and questioned about the cracks. The condition was referred to as "crazed cracking" and was claimed to have not caused a problem on any of the company's 22,000 manufactured cylinders. The "crazed cracks" were described as a common phenomenon that results from the permanent expansion the steel cylinder undergoes after testing. This permanent expansion maintains 
the steel cylinder in a state of compression and the composite wrap in a state of tension. To verify that this was the same condition encountered in the field, the manufacturer was sent photographs of the questionable cracks.

In addition to the structural safety of the cracks, the question was raised whether the cracks may permit unwanted exposure of the composite wrap to environmental elements (i.e., water, road salt, or dirt) or vehicle lubricants that result from component failures (i.e., engine oil, antifreeze, or power steering fluid). The manufacturer's representative suggested that a third-party retester be contacted if there were concerns regarding the safety of the cylinders, and that an appropriate third-party retester could be enlisted through the U.S. Department of Transportation or a local gas utility.

\section{Education}

Many site personnel lacked information about proper cylinder maintenance. They did not know what to look for in a visual inspection of the CNG cylinders and were unsure of the necessary frequency of visual inspections. They had not been given any guidelines or a recommended service interval for the inspections. Many maintenance personnel did not know where to go for cylinder service, recertifications, and on-vehicle cylinder inspections. The inspectors were able to provide some guidance during their visits, and gave copies of the CGA's Guidelines for Visual Inspection \& Requalification of Fiber Reinforced High Pressure Cylinders (CGA pamphlet No. C-6.2-1988) to maintenance personnel. The apparent breakdowns in the transfer of the necessary information to maintenance personnel point to a potentially larger problem. Site personnel need to have the proper training-which combines available information with the ability to interpret it-to adequately service and maintain the CNG cylinders and fuel systems. Without such training, the likelihood of vehicles operating with undetected damage or hazardous conditions increases.

\section{Conclusions and Recommendations}

\section{Conclusions}

\section{Inspections}

Inspectors visited DOE-sponsored sites where CNG-powered vehicles were in service and inspected the CNG cylinders and cylinder mounting systems for signs of damage and/or hazardous conditions. From the conditions encountered in the field, it is apparent that the manufacturers should take greater care when installing the cylinders and related items on the $\mathrm{CNG}$ vehicles. Many of the problems encountered on the buses could be eliminated, reducing the likelihood of accidents, if greater care were taken in removing any loose hardware (such as bolts and nuts), providing adequate length fuel lines that are not taut or rubbing against any other items, and positioning cylinder labels so that they can be easily viewed by site personnel.

The various mounting systems do have potentially hazardous design flaws. One system has a rubber insulator that does not completely isolate the cylinder from rigid metal contact with the steel support bracket. Another system's design allows debris or miscellaneous hardware to become wedged between the CNG cylinders and their supports. More than one system is constructed so that accessibility to the cylinders is limited, making cylinder removal for service or repair work an awkward and complicated procedure.

\section{Documentation}

A complete list of in-service vehicles, inspection results, cylinder manufacturers, site contacts, and site specifications has been developed. Additionally, a list of information on projected vehicles (those under construction) has been developed based on currently available information. This effort has helped to verify 
existing data in DOE records and provides a significant source of additional information for the DOE data base regarding buses and heavy-duty $\mathrm{CNG}$ vehicles at their sponsored sites.

In contacting manufacturers to determine cylinder information on vehicles still under construction, it was learned that the vehicle manufacturers typically wait until late in the construction phase to order and install the cylinders. Therefore, during the construction phase of the vehicle, the manufacturers might be able to provide the name of the cylinder manufacturer and the number of cylinders that will be used, but they will probably not know the serial numbers or certification dates of the cylinders until just before the vehicle is delivered. This factor should be taken into account when cylinder information on projected CNG vehicles is being documented.

\section{Education}

Inspectors were able to increase the education and awareness of certain site personnel in terms of cylinder damage and hazardous condition detection. Many site personnel did not know what to look for during a visual inspection of the CNG cylinders, what constituted a potential hazard, or what to do if a hazardous condition was detected. Site personnel appreciated the instruction and assistance provided by the inspectors. The site personnel's lack of knowledge about inspection guidelines points to an inadequate amount of readily available information and training on the subject. The site contact/shop foreman at each of the sites visited was given a copy of the CGA's Guidelines for Visual Inspection \& Requalification of Fiber Reinforced High Pressure Cylinders. These guidelines should prove helpful in providing more information to maintenance personnel. However, the CGA guidelines are not an interactive tool and cannot provide feedback.

\section{Recommendations}

\section{Gas Research Institute Recommended Inspection Procedure}

The GRI study on recent failures of $\mathrm{CNG}$ cylinders put forth similar recommendations [1]:

1. Composite hoop and full-wrapped cylinders currently in service should be visually inspected as soon as possible. The visual inspection should cover all areas of the cylinders, including the region underneath the tie-down straps. The recommendations of the CGA given in their publication CGA C-6.2, 1988, Guidelines for Visual Inspection and Requalification of Fiber Reinforced High Pressure Cylinders, should be followed. Because the CGA guidelines do not address stress corrosion cracking of composite cylinders, these should be used together with the recommendations given herein.

Stress corrosion cracks typically run along the length of the cylinder. The cracks may be opened, or may be tightly closed, which are harder to detect visually. Longitudinal stress corrosion cracks should not be confused with circumferential cracking of the matrix (referred to as crazed cracking in this report). Circumferential cracking of the matrix is typical of hoop wrapping and is not a cause for rejection of the cylinder. Cylinders exhibiting any visual longitudinal cracks should be removed from service immediately.

2. Cylinders should be mounted such that they will not be immersed in liquids. Examples of specific situations to be avoided include:

- Stone shields that lack adequate drainage of liquids

- Stone shields with adequate drainage when clean, but that may become clogged with solids over time 
- Cylinders mounted such that liquids can become trapped between adjacent cylinders, or the cylinder and the body of the vehicle.

3. If stone shields are used, they should not contact the cylinder. A specific situation to be avoided is:

- Stone shields mounted in direct contact with the cylinder and placed under the brackets that tie the cylinder to the frame. This is particularly important for metal stone shields, where crevice corrosion can acidify aqueous environments that may be present.

4. Metal brackets, and their supports should not be in direct contact with the cylinder. Any gaskets used to isolate the cylinders from the brackets should be of a resilient non-water retaining type so that they do not trap liquids in contact with the cylinder.

5. Cylinders should be mounted to ensure that they will not be exposed to corrosive agents. Cylinder installers should consider the potential for future modifications to the vehicle that may result in unanticipated exposure to a corrosive agent. A specific situation to be avoided is:

- Holes drilled in the bed of the truck that may drain liquid from the truck bed to underbody cylinders

\section{Future Visits}

Because of the cylinder problems encountered during the site visits, and because of the constantly changing status of CNG vehicles nationwide, maintaining high levels of vehicle safety through inspections should not be viewed as a one-time event, but as an ongoing process. It is recommended that inspections be made regularly, and that site personnel be trained to perform these inspections.

\section{References}

1. Gas Research Institute. (November 1994). GRI's Cylinder Safety Task Force Research Program and Recommendations to NGV Users. Prepared by the Cylinder Safety Task Force, Gas Research Institute, Chicago, Illinois.

2. Acurex Environmental Corporation. (September 7, 1994). Inspection of Compressed Natural Gas Cylinders on School Buses and Heavy-Duty Vehicles (Volume I-Technical Report). Final Report. Prepared under NREL Contract No. YCC-4-14238-01. Prepared by Acurex Environmental Corporation, Mountain View, California, for the National Renewable Energy Laboratory, Golden, Colorado.

3. Acurex Environmental Corporation. (September 7, 1994). Inspection of Compressed Natural Gas Cylinders on School Buses and Heavy-Duty Vehicles (Volume II - Fact Sheets). Final Report. Prepared under NREL Contract No. YCC-4-14238-01. Prepared by Acurex Environmental Corporation, Mountain View, California, for the National Renewable Energy Laboratory, Golden, Colorado.

4. Acurex Environmental Corporation. (September 7, 1994). Inspection of Compressed Natural Gas Cylinders on School Buses and Heavy-Duty Vehicles (Volume III - Photographs). Final Report. Prepared under NREL Contract No. YCC-4-14238-01. Prepared by Acurex Environmental Corporation, Mountain View, California, for the National Renewable Energy Laboratory, Golden, Colorado. 
5. Acurex Environmental Corporation. (January 31, 1995). Alternative-Fueled Truck Demonstration Natural Gas Program: Caterpillar G3406LE Development and Demonstration. Final Report. Prepared under CEC Contract No. 500-88-004; SCAQMD Contract No. 8913; SoCalGas Letter Agreement dated May 1, 1991; NREL Contract No. YD-2-11049-1; and TRI Contract No. 0323-94. Prepared by Acurex Environmental Corporation, Mountain View, California, for the California Energy Commission, Sacramento, California; the South Coast Air Quality Management District, Diamond Bar, California; the Southern California Gas Company, Los Angeles, California; the National Renewable Energy Laboratory, Golden, Colorado; and the Trucking Research Institute, Alexandria, Virginia. 
Appendix A

Inspection Protocol

A-1 


\section{Protocol for DOE CNG Cylinder Inspection}

\section{Site Visit Preparation}

Phone organization point of contact (POC) and obtain the following information:

- Name, phone number, and fax number of POC at vehicle site

- Number of CNG vehicles currently in service, and for each vehicle:

- Manufacturer

- Model year

- Model

- Application

- Delivery date

- In-service date

- ID number

- Number of CNG vehicles currently under construction, and for each vehicle:

- POC name and phone number for vehicle manufacturer

- Expected delivery dates of vehicles under construction

- Number of CNG vehicles projected for future use

Contact $\mathrm{POC}$ at vehicle site

- Verify information from organization POC

- Set up tentative inspection date, time, contact, and back-up contact for inspection

- Obtain directions to the site and emergency phone number for short notice contact

Contact manufacturer of vehicles under construction and obtain the following information:

- POC name and phone number for the cylinder manufacturer

- Number of cylinders to be installed

- Type of cylinder construction

- Cylinder size (diameter and length)

- Pressure rating (psi)

- Model number

- Certification type

- Serial numbers

- Proposed arrangement

- Method of mounting cylinders, including insulation

- Projected delivery dates

Contact manufacturer of cylinders for vehicles under construction

- Verify information from vehicle manufacturer

- Complete the list of cylinder information

Secure travel arrangements

- Air transportation

- Car transportation

Prepare Equipment

- Gather/acquire necessary equipment for inspections

- Review list before departure 


\section{Acurex \\ Environmental}

CORPORATION

A Geraghty \& Miller Company

\section{Protocol for DOE CNG Cylinder Inspection}

Page 2 of 2

\section{Arrival at Site}

Meet with site POC

- Explain reason/authority for the inspection and obtain the following information:

- average days per week each of the CNG vehicles are operated

- average times per week each of the CNG vehicles are fueled

- in-service dates for each of the CNG cylinders on the vehicles

Perform physical inspection of CNG vehicles for hazardous conditions

- Review conditions of:

- Fuel lines

- Cylinder manufacturer label

- Cylinder surface

- Cylinder shut-off valve

- Cylinder protective shielding

- Cylinder mounts and insulators

- Record findings on:

- Vehicle Identification Data Sheet

- CNG Cylinder Inspection Data Sheets

- In the event of damaged cylinders, tag for further inspection and phone NREL program officer

Photograph

- General site

- CNG fueling facility

- CNG vehicles

- Cylinder arrangement

- Individual cylinders

- Protective shielding for the cylinders

- Cylinder mounts and insulators

- Potentially hazardous conditions

Relate findings of inspection to site POC/supervisor

- Inform site POC of any problems noted during the inspection

- If any cylinders have been tagged, instruct the POC to:

- reduce the pressure in the damaged tank and isolate it from the remainder of the fuel system via the shut-off valve

- contact the cylinder manufacturer for a detailed inspection

- Leave copy of CGA guidelines for visual inspection of fiber-reinforced tanks

- Leave Acurex Environmental phone number and phone number of NREL contact

Wash-up and proceed to the next site 
Appendix B

Inspection Fact Sheets

B-1 
Site:

Address:

Mailing Address:

(if different)

Organization Contact:

Phone \#.

Fax \#:

Site Contact:

Phone \#:

Fax \#:

Veh. Manuf. Contact:

Phone \#:

Fax \#:

\# of CNG Vehicles: On-Site

Under Construction

Proposed

\begin{tabular}{|c|c|c|c|c|c|c|c|}
\hline$\sqrt{\text { eh }}$ & $\overline{\text { Year }}$ & Manufacturer & Model & Application & Delivery Date & In-Service Date & Vekicle ID\# \\
\hline 1 & & & & & & & \\
\hline 2 & & & & & & & \\
\hline 3 & & & & & & & \\
\hline 4 & & & & & & & \\
\hline 5 & & & & & & & \\
\hline & & & & & & & \\
\hline
\end{tabular}




\section{Vehicle Identification Data Sheet} of

Site:

Information Basis: On-Site Inspection

Inspection Date:

Average Days Operated per Week.

Emergency Vent System: $\mathrm{Y} / \mathrm{N}$

Cylinder Manufacturer.

Address:

Phone \#:

Hazardous and/or Unusual Conditions:

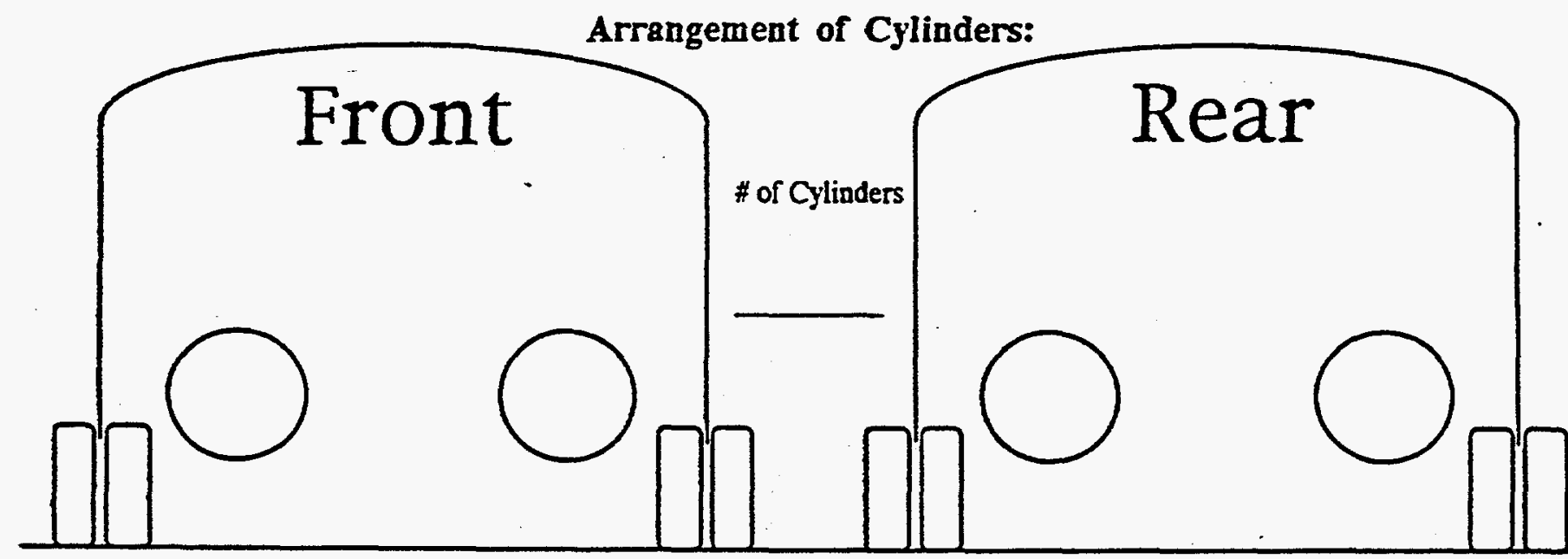

Inspector/Surveyor:

Average of Times Fueled per Week:
Reserve Tank: $Y / N$

\section{Hazardous andor Unusual Conditions:}

Vehicle ID\#:

Telephone 


\section{Acurex}

of

Site:

Vehicle ID:

Cyl. In-Service Date:

Computed \# of Fueling Cycles:

Approximate Cyl. Size (inches):

Diameter

Length

Manufacturer Labei:
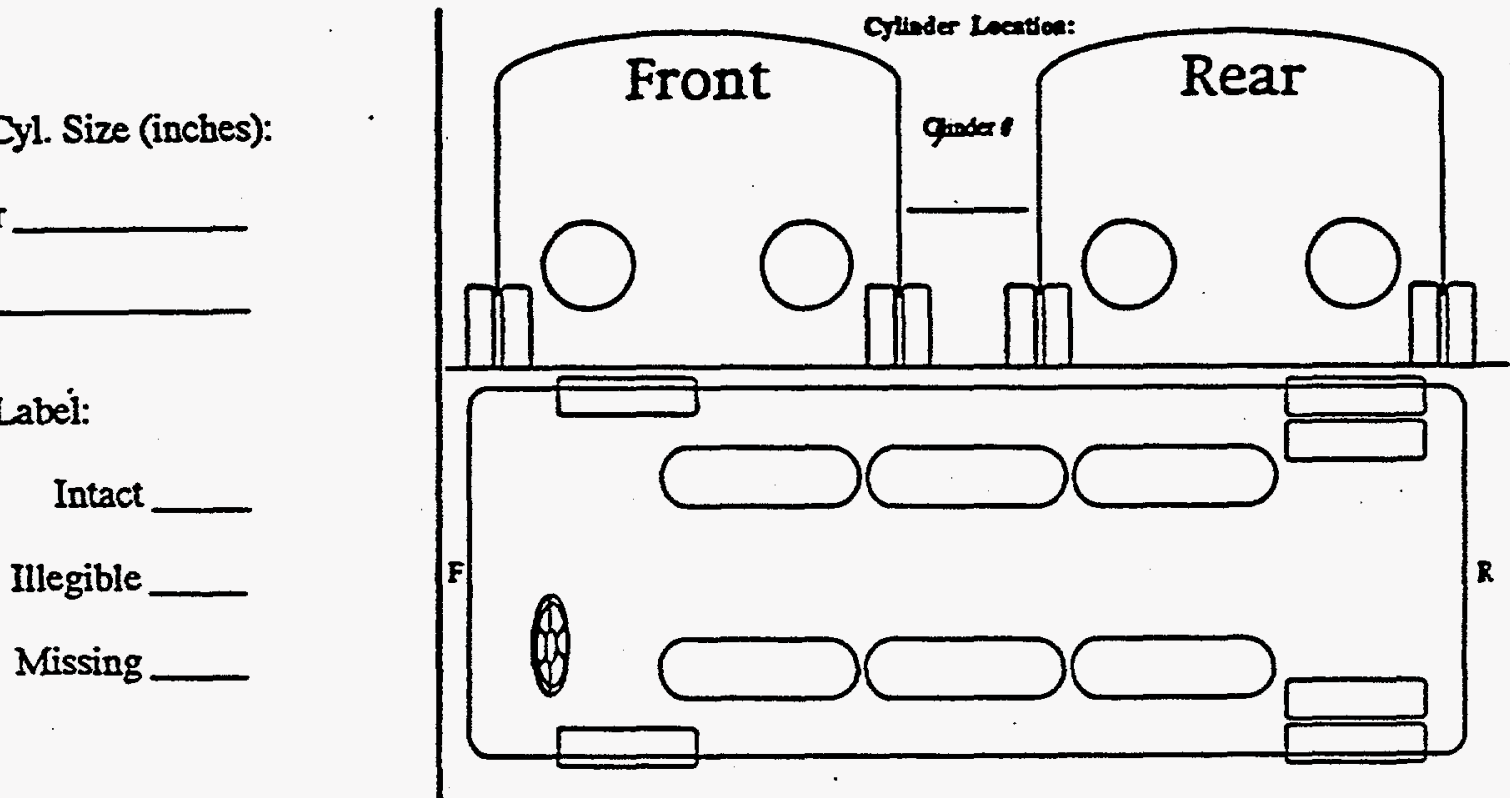

Comments

Cyl. Manufacturer.

Model \#.

Certification Type: DOT

ASME

Certification Date:

Pressure Rating (psi): 2400

Type of Construction: Steel

Aluminum

Full Composite
ID (Serial)

NGV2

Other (Specify)

Recertification Date:

3600 Other (Specify)

Composite Reinforced Steel

Composite Reinforced Aluminum

Other (Specify)

Comments: 


\section{Acurex}

CNG Cylinder Inspection Data Sheet 2 Page of

Condition of Fuel Lines: Good

Questionable/Require Further Inspection

Comments:

Visual Review of Cylinder Suface:

Abrasions/Scratches:

Dents/Impacts:

Fire/Burn Marks:

Diagram of Cylinder Damage:
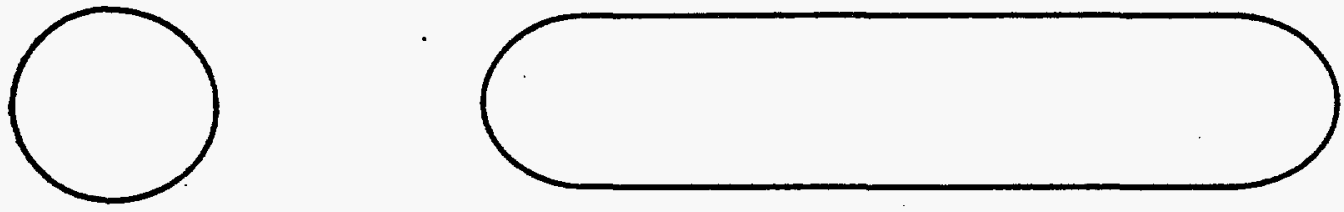

Minor

None

Minor

None

Minor

None

Comments:

Photographs Taken of Cylinder: (check)

Cylinder Shut-Off Valve:

Condition of Valve: Good Questionable/Require Further Inspection:

None:

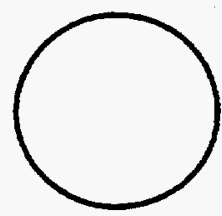

Protective Shielding for Cylinder:

Yes No

Description:

Condition of Shielding:

Photograph Taken of Shielding: (check) 

of

Condition of cyl. Mounts: Good __ Questionable/Require Further Inspection

Condition of cyl. Insulators: Good ___ Questionable/Require Further Inspection Comments:

Diagram of Cylinder Mounts:
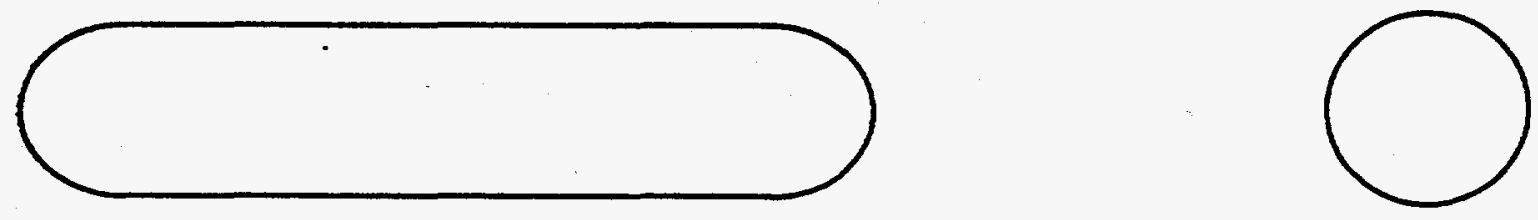

Photograph Taken of Cylinder Mounts: (check)

Hazardous and/or Other Unusual Conditions:

Cylinder Inspection Summary:

No Damage Detected

Requires Further Inspection/Repair

Cylinder Tagged by Inspector

Site Contact Notified to Isolate Tank

NREL Representative Contacted 


\section{Appendix C}

\section{Description of Vehicle Cylinder Mountings}

This appendix describes the different cylinder mounting arrangements encountered during site visits. These descriptions were supplemented by the photographs in Volume III of the original CNG Cylinder Inspection report.

\section{Type 1}

The Type 1 buses were fitted with either four or six CNG cylinders. Three different cylinder arrangements were found. On the buses with four cylinders, two of the cylinders were mounted mid-vehicle, between the front and rear wheels. The cylinders were mounted longitudinally and outside the chassis with one on each side of the vehicle. The remaining two cylinders were mounted in a similar orientation, but placed behind the rear wheels.

On the buses with six cylinders, the first arrangement had six cylinders mounted mid-vehicle, between the front and rear wheels. Three cylinders were mounted end to end outside the chassis on the driver side and three were mounted end to end outside the chassis on the passenger side. The second arrangement had four of the cylinders mounted mid-vehicle, between the front and rear wheels, where two cylinders were mounted end to end outside the chassis on the driver side and two were mounted end to end outside the chassis on the passenger side. The remaining two cylinders were mounted in a similar orientation, but placed behind the rear wheels.

The cylinders were mounted within a carrier and had a gravel guard shield along the bottom for the full length of the carrier. The distance from the road to the carrier gravel guard was approximately 16 in. The carrier front and rear ends were heavily reinforced with steel channel to protect the cylinder shut-off valve and fuel lines. The cylinders were clamped to the carrier with a two-piece heavy steel band. The lower piece of the steel band was welded to the carrier in four places and was stationary within the carrier. The upper support band clamped the cylinder to the lower band. Rubber insulators were located between the support bands and cylinders. There were two supports per cylinder set approximately 18 in. from each cylinder end. The carrier, in turn, was bolted to the vehicle chassis frame rail. Figure C-1 is a sketch of the cylinder supports.

\section{Type 2}

The Type 2 buses were fitted with four CNG cylinders located behind the rear wheels of the vehicles. The cylinders were installed longitudinally and were parallel to one another. The two inboard cylinders were mounted between the chassis frame rails and the two outboard cylinders were mounted to the outside of the frame rails. The cylinders were secured by a two-piece heavy steel band which clamped them in place. There were two support bands per cylinder set approximately 18 inches from each cylinder end. Rubber insulators were located between the support bands and cylinders. The bands clamped the cylinder and were in turn bolted to the chassis. All cylinder supports were fastened to, and supported by, the chassis frame. No cylinder brackets or shields were fastened to the school bus body. The engine exhaust pipe was heat shielded because of its close proximity to some of the CNG cylinders. No gravel guard shields were included in the Type 2 design. Figure C-2 is a sketch of the inboard cylinder supports. 


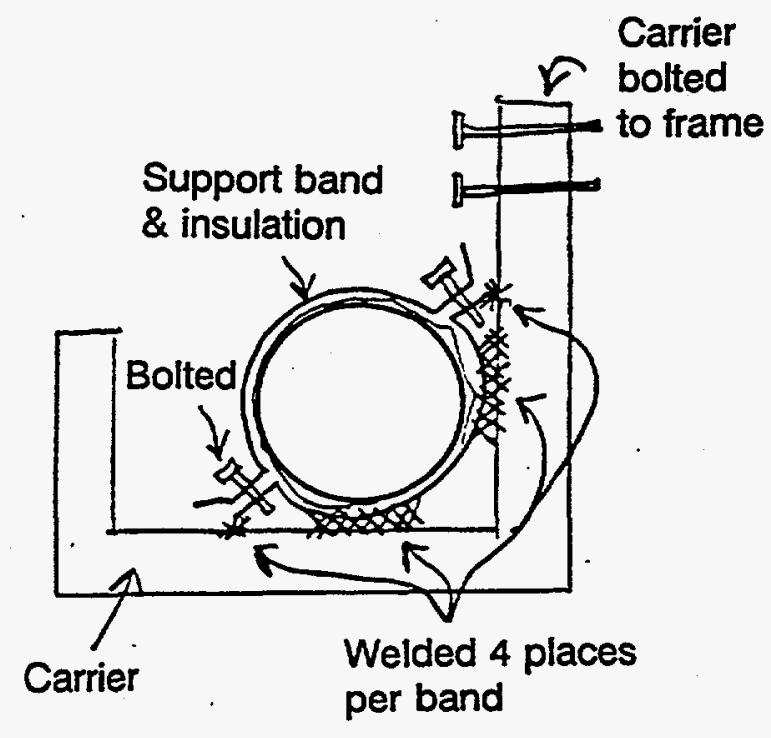

Figure C-1. Type 1 cylinder supports
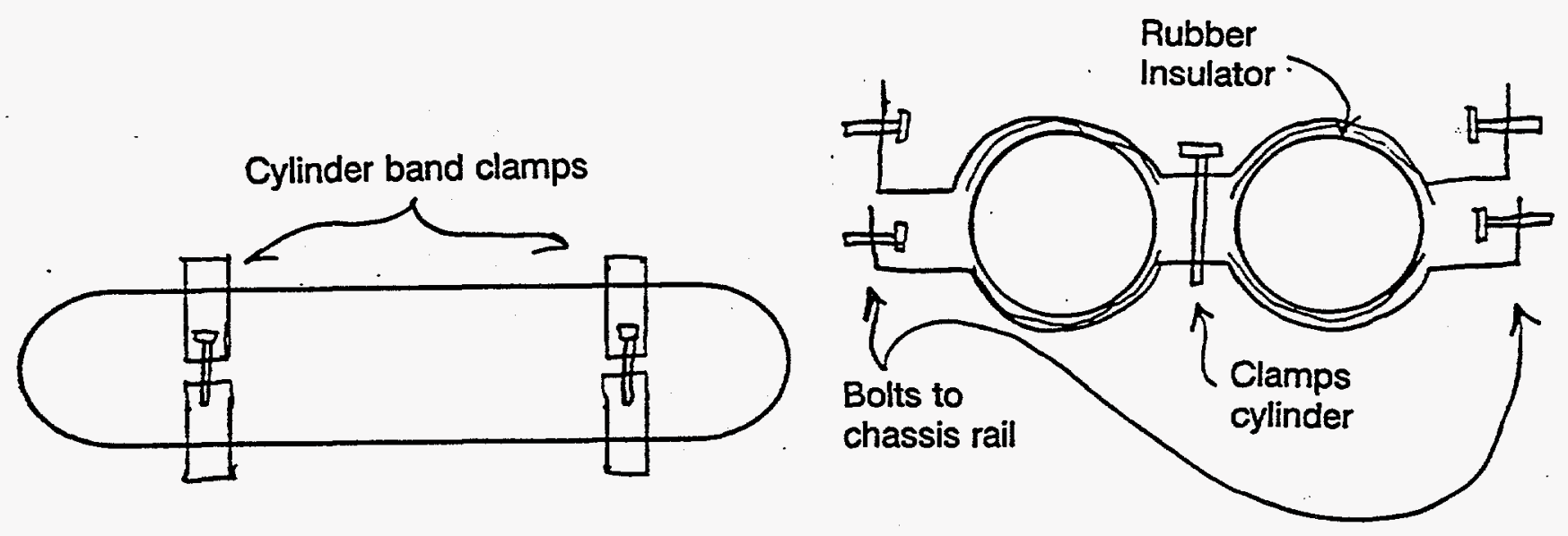

Figure C-2. Type 2 inboard cylinder supports 
The outboard cylinder support band cantilevered the cylinders off the frame to avoid attachment of the support to the body of the vehicle. A heavy rectangular steel shielding was positioned in front of the outboard cylinders to protect the cylinder shut-off valve and fuel lines. Figure C-3 is a sketch of the outboard cylinder supports.

\section{Type 3}

The Type 3 buses were fitted with either four or six CNG cylinders. In the four-cylinder design, the cylinders were installed side by side in a row beneath the bus just aft of the rear wheels. Two of the cylinders were set between the chassis frame rails; the other two cylinders were mounted outside of the frame rails. The cylinders were secured by a one-piece steel band that threaded through an intermediate bracket and clamped the cylinder in place. The intermediate bracket was in turn bolted to a support fixture that was bolted to the chassis. There were two support bands per cylinder set approximately 18 in. from each cylinder end. Rubber insulators were located between the support bands and cylinders. All cylinder brackets were fastened to and supported by the chassis frame. No cylinder brackets or shields were fastened to the school bus body. The inboard cylinder intermediate brackets were bolted to a cross brace mounted between, and perpendicular to, the two chassis frame rails. This design provided the inner cylinders with a 14-in. ride height from road to cylinder lower surface. A gravel guard was mounted across the front section of the inner cylinders. Figure C-4 is a sketch of the inboard cylinder supports.

In the six-cylinder design, two additional cylinders were mounted directly behind the existing outboard cylinders, one on the driver side and one on the passenger side. The intermediate brackets of the outboard cylinders were bolted to an L-shaped support bracket that cantilevered the cylinders off the chassis frame rail. The distance from the road to the underside of the outboard cylinder was approximately $20 \mathrm{in}$. The outboard cylinders were surrounded by, but not supported by, a protective cage. The cage was bolted to the vehicle chassis frame rail. The front and rear ends of the cage were heavily reinforced with steel channel to protect the cylinder shut-off valve and fuel lines. Figure C-5 is a sketch of the outboard cylinder supports.

\section{Type 4}

The Type 4 buses had three cylinders mounted behind the rear wheels. The cylinders were installed longitudinally and parallel to one another. Two of the cylinders were mounted between the chassis frame rails; the third cylinder was mounted to the outside of the driver side chassis frame rail. The cylinders were secured by a two-piece heavy steel band that clamped the cylinder in place. There were two support bands per cylinder set approximately 18 in. from each cylinder end. Rubber insulators were located between the support bands and cylinders. The bands clamped the cylinder and were in turn bolted to the chassis. All cylinder brackets were fastened to and supported by the chassis frame. No cylinder brackets or shields were fastened to the school bus body. No gravel guard shields were included in this design. Figure C-6 is a sketch of the inboard cylinder supports.

The outboard cylinder support bands cantilevered the cylinder off the chassis frame rail to avoid attachment of the cylinder supports to the body of the vehicle. A heavy rectangular steel shield was positioned in front of the outboard cylinder to protect the cylinder shut-off valve and fuel lines. Figure C-7 is a sketch of the outer cylinder supports. 

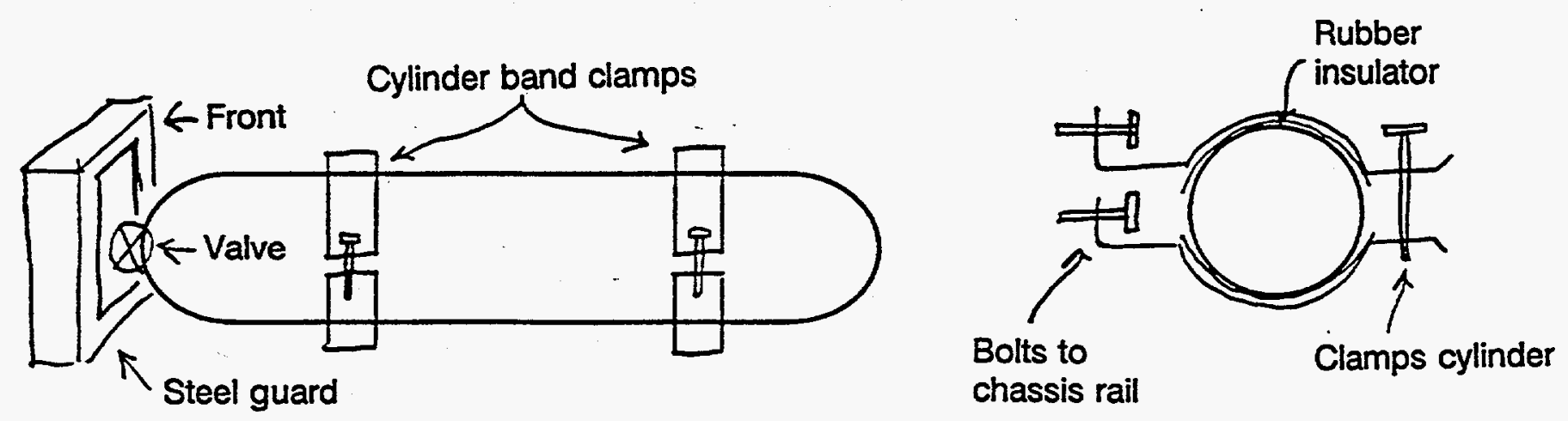

Figure C-3. Type 2 outboard cylinder supports
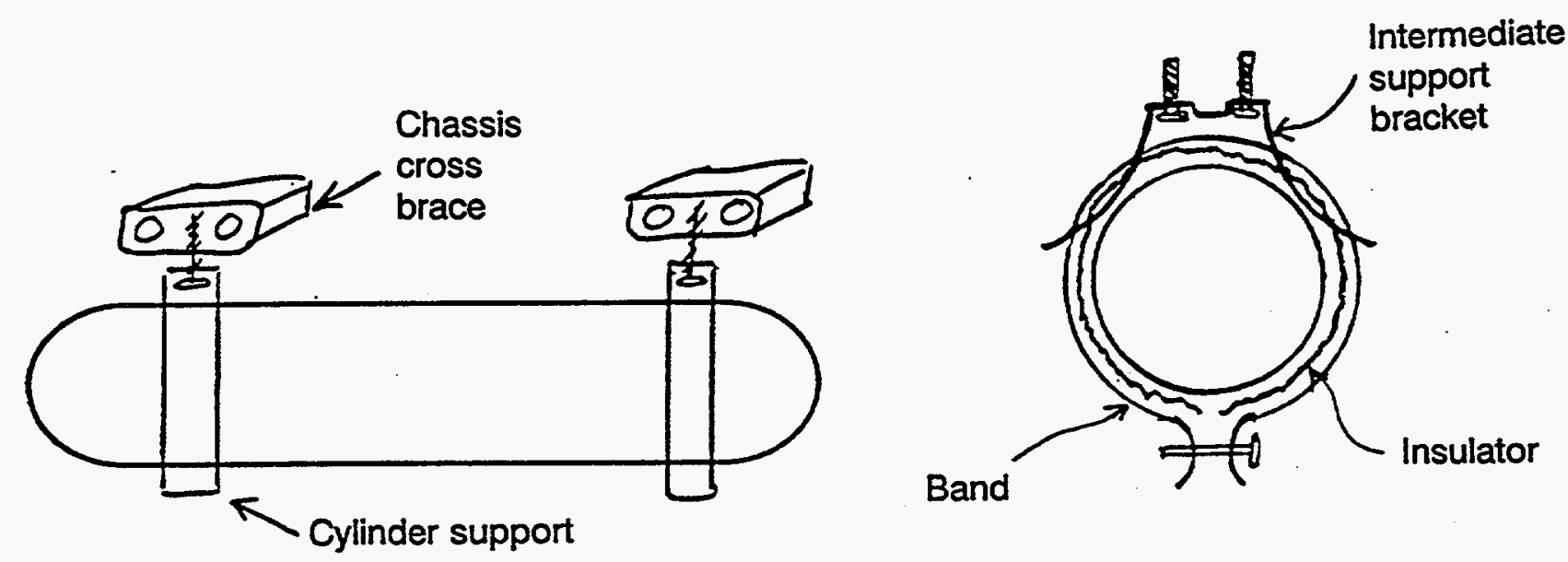

Figure C-4. Type 3 inboard cylinder supports 


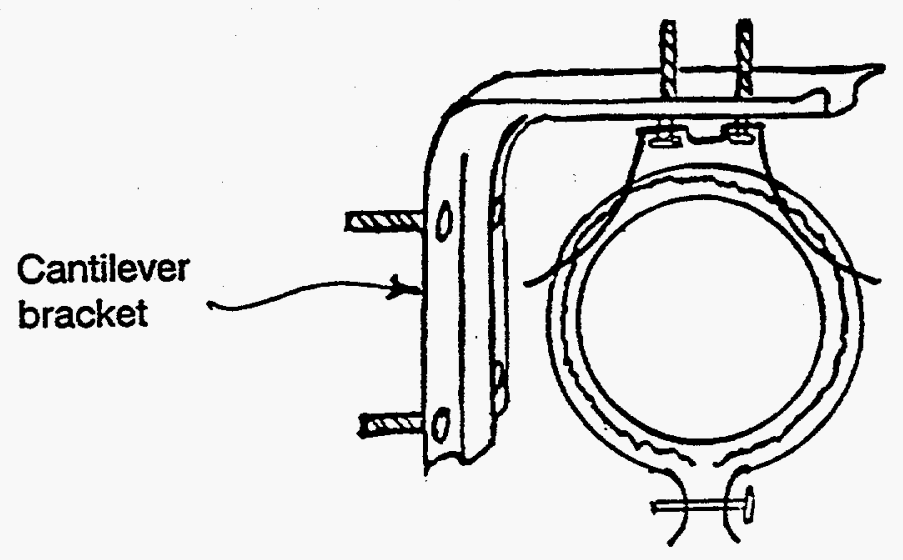

Figure C-5. Type 3 outboard cylinder supports

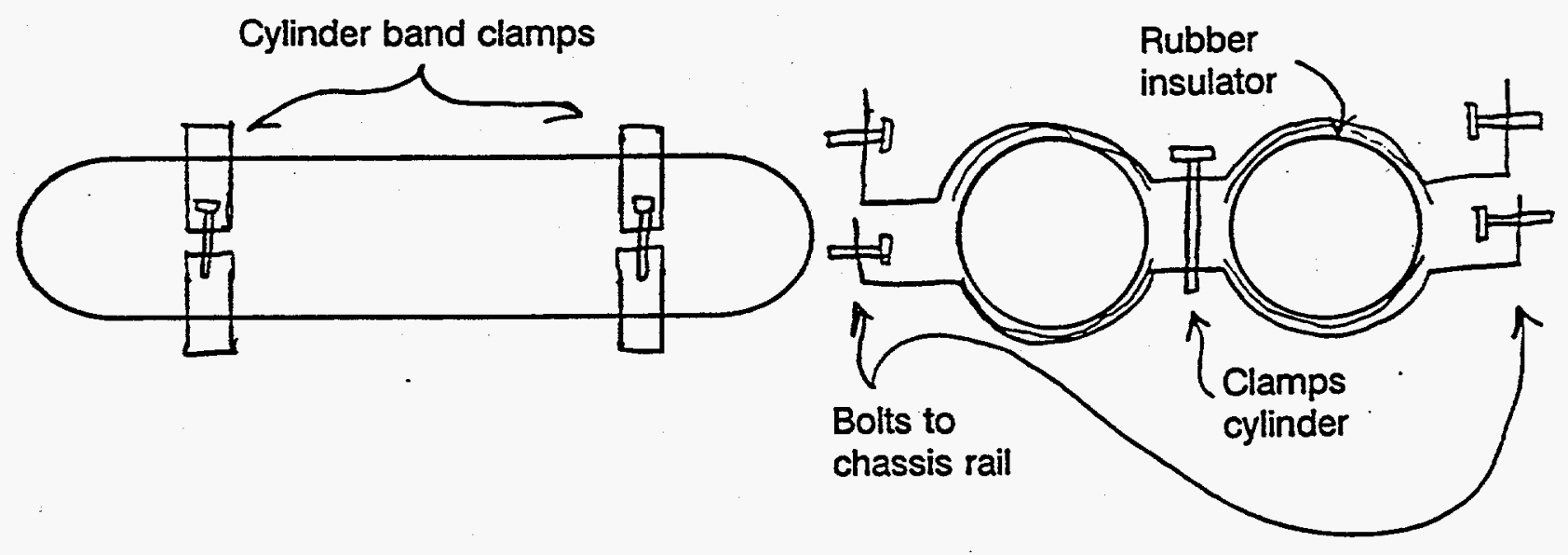

Figure C-6. Type 4 inboard cylinder supports 

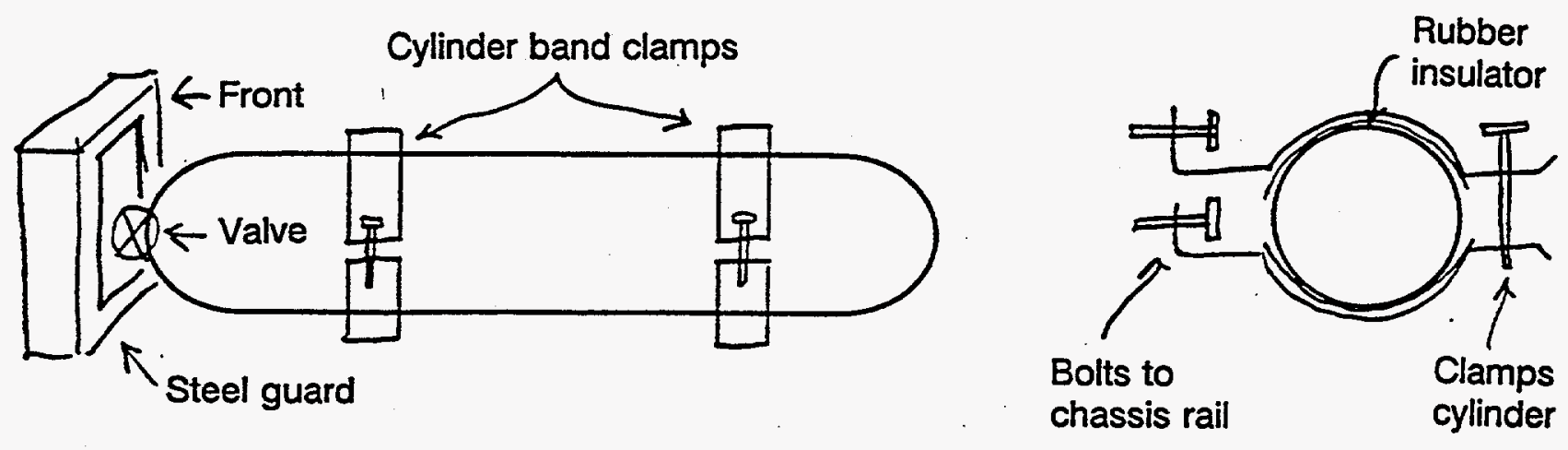

Figure C-7. Type 4 outboard cylinder supports 
ublic reporting burden for this collection of information is estimated to average 1 hour per response including the time for reviewing instructions, searching existing data ources, gathering and maintaining the data needed, and completing and reviewing the collection of information. Send comments regarding this burden estimate or any other spect of this collection of information, including suggestions for reducing this burden, to Washington Headquarters Services, Directorate for Information Operations and leports, 1215 Jefferson Davis Highway, Suite 1204, Artington, VA 22202-4302, and to the Office of Management and Budget, Paperwork Reduction Project (0704-0188), Vashington, DC 20503

\begin{tabular}{|l|l|l|}
\hline AGENCY USE ONLY (Leave blank) & $\begin{array}{l}\text { 2. REPORT DATE } \\
\text { July } 1995\end{array}$ & $\begin{array}{l}\text { 3. REPORT TYPE AND DATES COVERED } \\
\text { Subcontract report }\end{array}$ \\
\hline
\end{tabular}

TITLE AND SUBTITLE

ispection of Compressed Natural Gas Cylinders on School Buses

\section{AUTHOR(S)}

curex Environmental Corporation

PERFORMING ORGANIZATION NAME(S) AND ADDRESS(ES)

lcurex Environmental Corporation

55 Clyde Avenue

.0. Box 7044

Mountain View, CA 94039

\section{SPONSORING/MONITORING AGENCY NAME(S) AND ADDRESS(ES)}

Jational Renewable Energy Laboratory

617 Cole Boulevard

folden, CO 80401-3393

\section{SUPPLEMENTARY NOTES}

2a. DISTRIBUTION/AVAILABILITY STATEMENT

Jational Technical Information Service

J.S. Department of Commerce

285 Port Royal Road

pringfield, VA 22161

\section{ABSTRACT (Maximum 200 words)}

he U.S. Department of Energy (DOE) is sponsoring compressed natural gas-powered school bus vehicle demonstrations in various locations around the country. Farly in 1994, two non-DOE-sponsored compressed natural gas vehicles equipped with composite-reinforced-aluminum fuel cylinders experienced cylinder ruptures uring refueling. Subsequent inspections revealed that the cylinder composite materials were damaged, which led to the ruptures. Ensuring the safety of the ompressed natural gas vehicles it sponsors is of paramount importance to DOE, so the department directed the National Renewable Energy Laboratory to conduct ispections of DOE-sponsored vehicles nationwide. Following the inspections, the inspectors made the recommendations described in this report, which are urrently being implemented.

\section{SUBJECT TERMS}

Iternative fuels, vehicle safety, compressed natural gas safety 27

16. PRICE CODE

7. SECURITY CLASSIFICATION
OF REPORT

18. SECURITY CLASSIFICATION OF THIS PAGE
19. SECURITY CLASSIFICATION OF ABSTRACT
8. PERFORMING ORGANIZATION REPORT NUMBER

DE95009231

10. SPONSORING/MONITORING AGENCY REPORT NUMBER

NRELTP-425-7629 12b. DISTRIBUTION CODE

UC 1504

\section{SN 7540-01-280-5500}

